\title{
Telomere maintenance pathway activity analysis enables tissue- and gene-level inferences
}

\author{
Lilit Nersisyan ${ }^{1,2 *}$, Arman Simonyan ${ }^{1}$, Hans Binder ${ }^{3}$, Arsen Arakelyan ${ }^{1,2}$ \\ ${ }^{1}$ Bioinformatics Group, Institute of Molecular Biology, National Academy of Sciences, Yerevan, \\ Armenia \\ ${ }^{2}$ Pathverse, LLC, Yerevan, Armenia \\ ${ }^{3}$ Interdisciplinary Center for Bioinformatics, University of Leipzig, Leipzig, Germany \\ * Correspondence: \\ Lilit Nersisyan \\ Keywords: telomere maintenance mechanisms, telomerase, alternative lengthening of telomeres, \\ pathway signal flow, testis
}

\begin{abstract}
Telomere maintenance is one of the mechanisms ensuring indefinite divisions of cancer and stem cells. Good understanding of telomere maintenance mechanisms (TMM) is important for studying cancers and designing therapies. However, molecular factors triggering selective activation of either the telomerase dependent (TEL) or the alternative lengthening of telomeres (ALT) pathway are poorly understood. In addition, more accurate and easy-to-use methodologies are required for TMM phenotyping. In this study, we have performed literature based reconstruction of signaling pathways for the ALT and TEL TMMs. Gene expression data were used for computational assessment of TMM pathway activities and compared with experimental assays for TEL and ALT. Explicit consideration of pathway topology makes bioinformatics analysis more informative compared to computational methods based on simple summary measures of gene expression. Application to healthy human tissues showed high ALT and TEL pathway activities in testis, and identified genes and pathways that may trigger TMM activation. Our approach offers a novel option for systematic investigation of TMM activation patterns across cancers and healthy tissues for dissecting pathwaybased molecular markers with diagnostic impact.
\end{abstract}

\section{Introduction}

Telomeres perform protective functions at the ends of linear eukaryotic chromosomes. They constitute one of the basic molecular factors conditioning the ability of cells to divide. Excessive cell divisions lead to incomplete reconstitution of telomeres resulting in telomere shortening and loss of proper structure of telomeric ends (Blackburn, 1991; Chow et al., 2012; Martínez and Blasco, 2015). Highly proliferative cells, such as cancer and stem cells, may utilize mechanisms for preserving the telomere ends despite many rounds of divisions (Greenberg, 2005). These are known as telomere maintenance mechanisms (TMMs, (Hug and Lingner, 2006)). The cells may trigger activation of different TMM pathways, either using the telomerase reverse transcriptase driven synthesis (TEL (Hug and Lingner, 2006; Shay, 2016)), or via DNA breakinduced repair (BIR) like processes, also known as alternative lengthening of telomeres (ALT (Cesare and Reddel, 2008; Neumann et al., 2013; Sobinoff and Pickett, 2017; Jia-Min Zhang et al., 2019)). The TEL pathway is more commonly occurring in stem cells and the majority of cancers, while ALT is mostly activated in tumors of mesenchymal and neuroepithelial origin (liposarcomas, osteosarcomas and oligodendroglial gliomas), but can also be found in tumors of epithelial origin (carcinomas of the breast, lung and kidney) (Henson et al., 2002). Some cancers such as neuroblastomas and liposarcomas, do not show evidence for activation of any of the two TMM pathways, exhibiting the ever shorter 
telomeres phenotype (Costa et al., 2006; Dagg et al., 2017). Finally, some indications have recently prompted that certain cancer entities (liposarcoma and other sarcomas, some tumor types) might also have both of the TMM pathways activated (Costa et al., 2006; Gocha et al., 2013).

Current experimental assays for TMM phenotyping have several shortcomings. For example, the telomeric-repeat amplification protocol (TRAP) assay for estimating telomerase activity is not very sensitive and time and resource consuming (Fajkus, 2006). Assays to measure ALT activity are based on the assessment of chromosomal and/or cellular markers, such as C-circles, ALT-associated nuclear bodies or heterogeneous distributions of telomere length (Pickett and Reddel, 2015; Jia-Min Zhang et al., 2019), which all are usually observed in ALTtype cancers. However, recent studies strongly suggests that none of these markers alone is sufficient to define the ALT status of a cell (Jia-Min Zhang et al., 2019). Attempts to use gene expression signatures for classification of TMM mechanisms have been made (Lafferty-Whyte et al., 2009). However, those signatures are applicable to specific data (Lafferty-Whyte et al., 2009) and they do not provide mechanistic details about TMM pathway activation.

Here we were set to develop a complementary approach to TMM detection that utilizes widely available gene expression data in combination with the molecular interaction topologies in the TMM pathways. Establishment and analysis of TMM pathway topologies is not a trivial issue, because there is no holistic understanding of the functional context of the molecular factors, of their interactions and of the mechanisms triggering TMM activation. Previous research has identified transcriptional regulators of the assembly of the telomerase complex (Yuan et al., 2019), however, how the enzyme components are processed and brought together (Schmidt and Cech, 2015), how the enzyme is recruited to the telomeres and what promotes final synthesis (Chen et al., 2012), is largely not clear and scattered throughout the literature in the best case.
Even less is known about regulation of ALT on a gene level. Although it is considered as a breakinduced repair (BIR)-like process, some of the usually accepted BIR factors are not always involved (Jia-Min Zhang et al., 2019). We previously developed a TMM-pathway approach under consideration of TEL and ALT and applied it to colon cancer (Nersisyan et al., 2019). However, overall there is no pathway representation, neither of TEL, nor of ALT TMM, which has been proven in a wider context of cells and/or tissues.

In the first part of the manuscript, we show how gene expression data can be used for TMM phenotyping making use of the TEL and ALT pathways, which were constructed based on available knowledge about molecular factors and interactions of TMM by further developing our previous work (Nersisyan et al., 2019). For demonstration we have analyzed available gene expression data on different cancers with independent experimental TMM annotations (Lafferty-Whyte et al., 2009). In the second part, we apply comprehensive bioinformatics analyses to discover details of TEL and ALT activation in healthy human tissues.

\section{Results}

\subsection{Literature based reconstruction of telomere maintenance pathways}

In order to address the current lack of signalling pathway representations of telomere maintenance mechanisms (TMMs), we have performed a literature search to identify genes involved in TEL and/or ALT TMMs and to define their interaction partners and functional role (Figure 1). Overall, we identified 38 (ALT) and 27 (TEL) genes derived from 19 and 13 references, respectively (Tables 1 and 2). We have considered interactions among these genes in terms of pathway topologies and took into account complex formation and other molecular events with possible impact for TEL or the ALT TMM in order to describe pathway activation in time and space (Figure 1). 
bioRxiv preprint doi: https://doi.org/10.1101/2021.02.01.429081; this version posted February 2, 2021. The copyright holder for this preprint (which was not certified by peer review) is the author/funder, who has granted bioRxiv a license to display the preprint in perpetuity. It is made frontiers available under aCC-BY-NC-ND 4.0 International license.

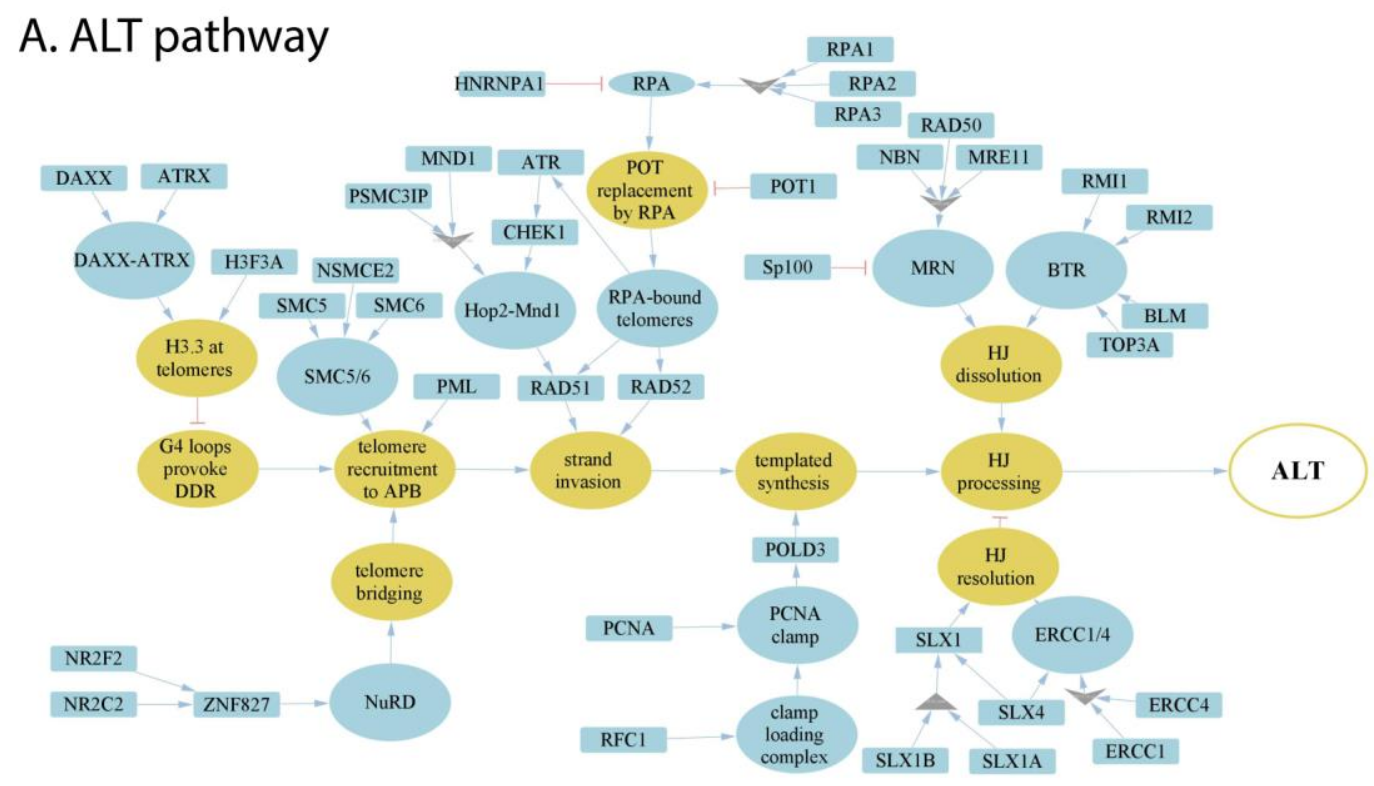

\section{B. TEL pathway}

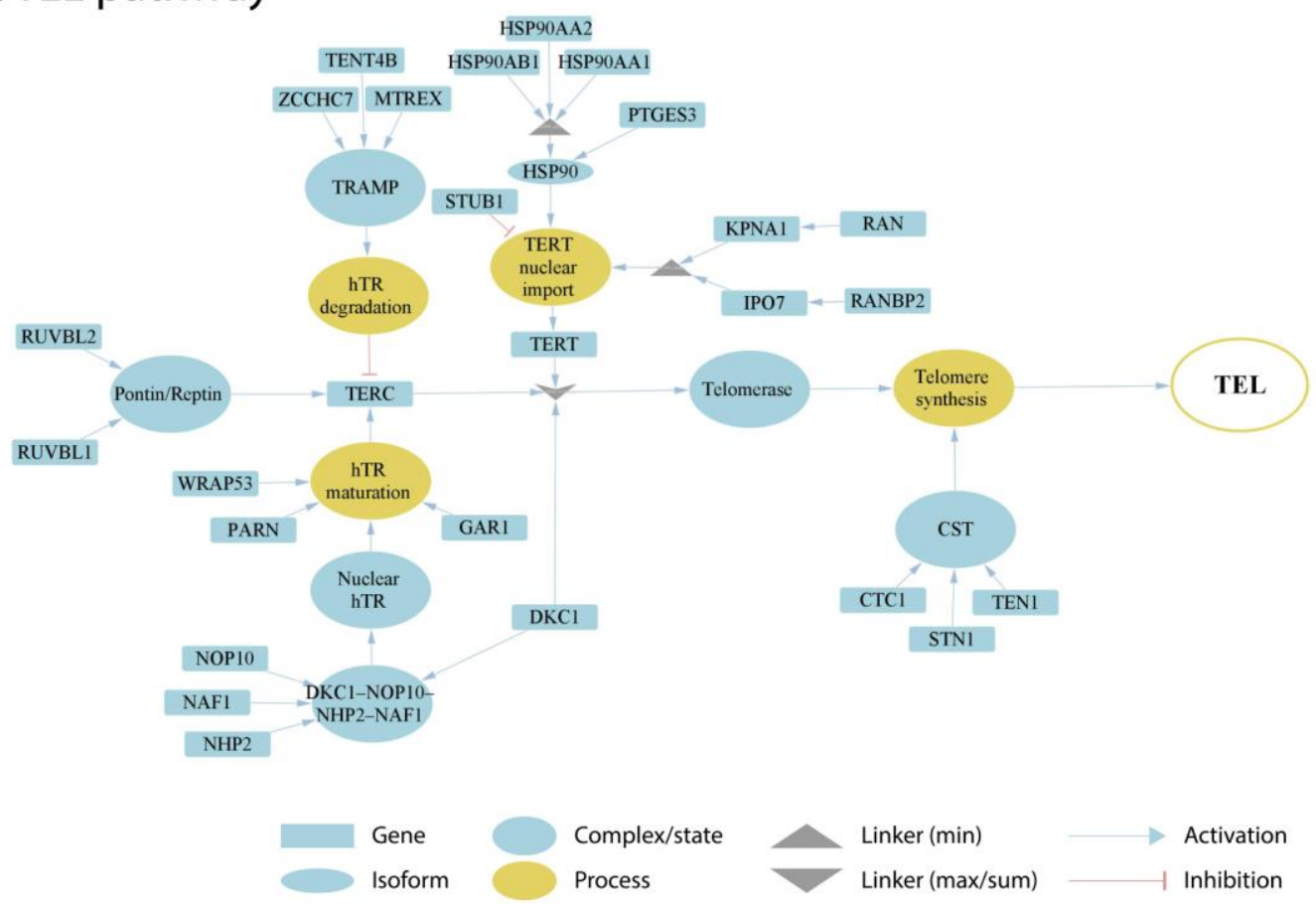

Figure 1. Literature based reconstruction of the ALT and the TEL pathways of telomere maintenance.

The ALT and TEL pathways include 37 and 26 genes based on 19 and 13 unique citations, respectively. The events leading to telomere maintenance in each pathway converge at respective final sink nodes (open circles at the right). Types of nodes and edges are defined in the figure. Linker nodes apply different operators for describing signal transduction by taking minimum or maximum values of all the input signals or their sum (see legend in the figure).

Hereby, the ALT pathway is represented through a series of branches describing DNA damage and assembly of APB bodies, which then promote separation of one of the telomere strands and invasion to another telomeric template from sister chromatids, other chromosomes or extra- chromosomal telomeric sequences, followed by DNA polymerase delta assisted telomere synthesis and ultimate processing of Holliday junctions, which is formed during the strand invasion (Figure 1A) (Henson et al., 2002; Pickett and Reddel, 2015; Jia-Min Zhang et al., 2019; Sobinoff and Pickett, 
2020). The TEL pathway describes expression, posttranscriptional modifications, recruitment and assembly of different components of the telomerase complex, namely hTERT, hTR and dyskerin, followed by the formation of a catalytically active telomerase complex, its recruitment to telomeres and telomere synthesis by telomerase and DNA polymerase alpha (Figure 1B)(Hug and Lingner, 2006; Tseng et al., 2015; Rice and Skordalakes, 2016).

\subsection{TMM pathway activities are supported by experimental test assays}

For assessment of TEL and ALT TMM pathway activities in a given sample we use gene expression data and the pathway signal flow (PSF) algorithm as implemented in Cytoscape (apps PSFC and $T M M$; see methods section for details). The algorithm computes the PSF score in each of the pathway nodes by considering signal propagation through all upstream activating and inhibiting interactions and complex and linker node types making use of the fold change (FC) expression values of the involved pathway genes with respect to their mean expression in the respective data set. The PSF score thus reflects the activity of all upstream events and of their topology in contrast to gene set overexpression measures often used alone for functional assessment (Hakobyan et al., 2016; Nersisyan et al., 2017). The PSF scores of the final sink nodes then estimate the overall activity of the TEL and the ALT pathway, respectively.

Application to two publicly available microarray gene expression datasets from cell lines and liposarcoma tissues delivers an ALT/TEL-PSF data couple for each sample, which is then plotted into an ALT-versus-TEL PSF coordinate systems (Figures 2A, B). Each sample is color-coded according to its assignment to $\mathrm{TEL}^{+} / \mathrm{TEL}^{-}$or $\mathrm{ALT}^{+} / \mathrm{ALT}^{-}$or double negative $\mathrm{ALT}^{-} / \mathrm{TEL}^{-}$phenotypes which were determined by independent experimental assays alongside with the gene expression measurements. Using support vector machine learning, TEL positive and negative samples were separated by a vertical line, and ALT positive and negative samples by a horizontal line in both data sets (Figure 2A, B). 
bioRxiv preprint doi: https://doi.org/10.1101/2021.02.01.429081; this version posted February 2, 2021. The copyright holder for this preprint (which was not certified by peer review) is the author/funder, who has granted bioRxiv a license to display the preprint in perpetuity. It is made frontiers

A

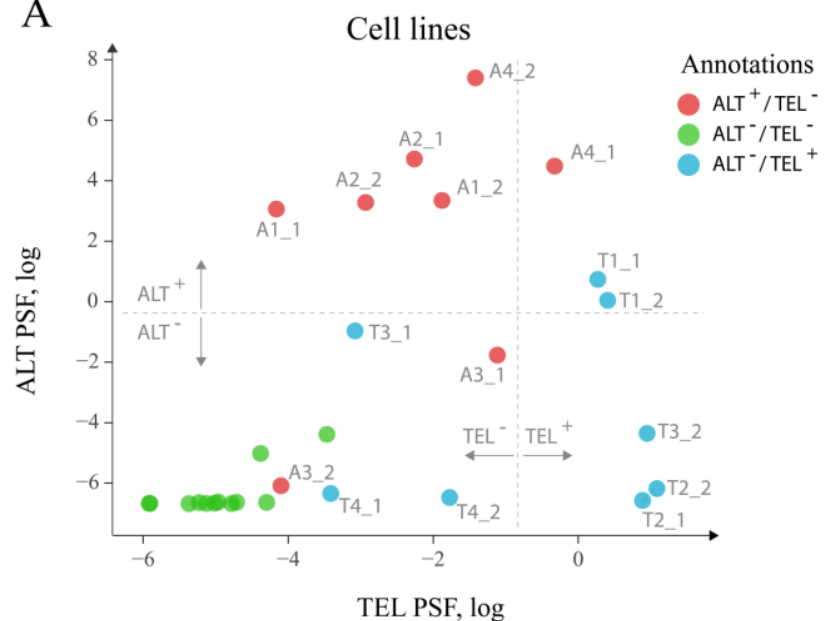

canthes
B

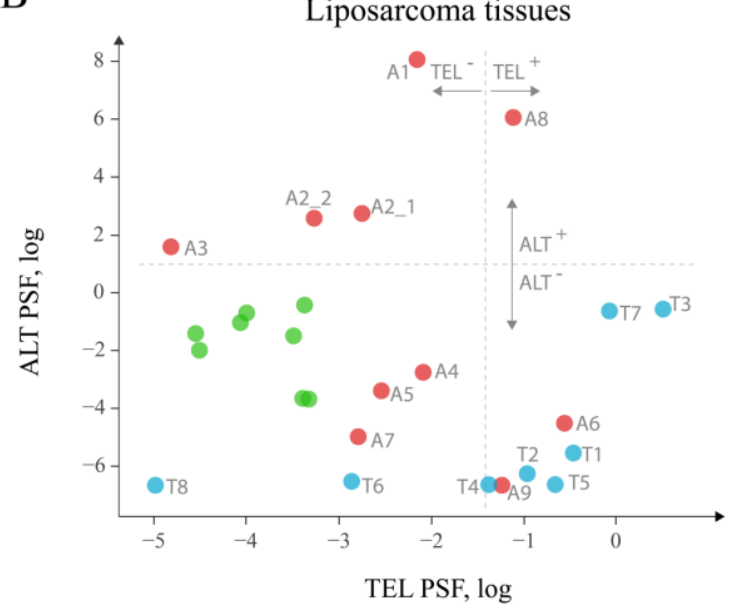

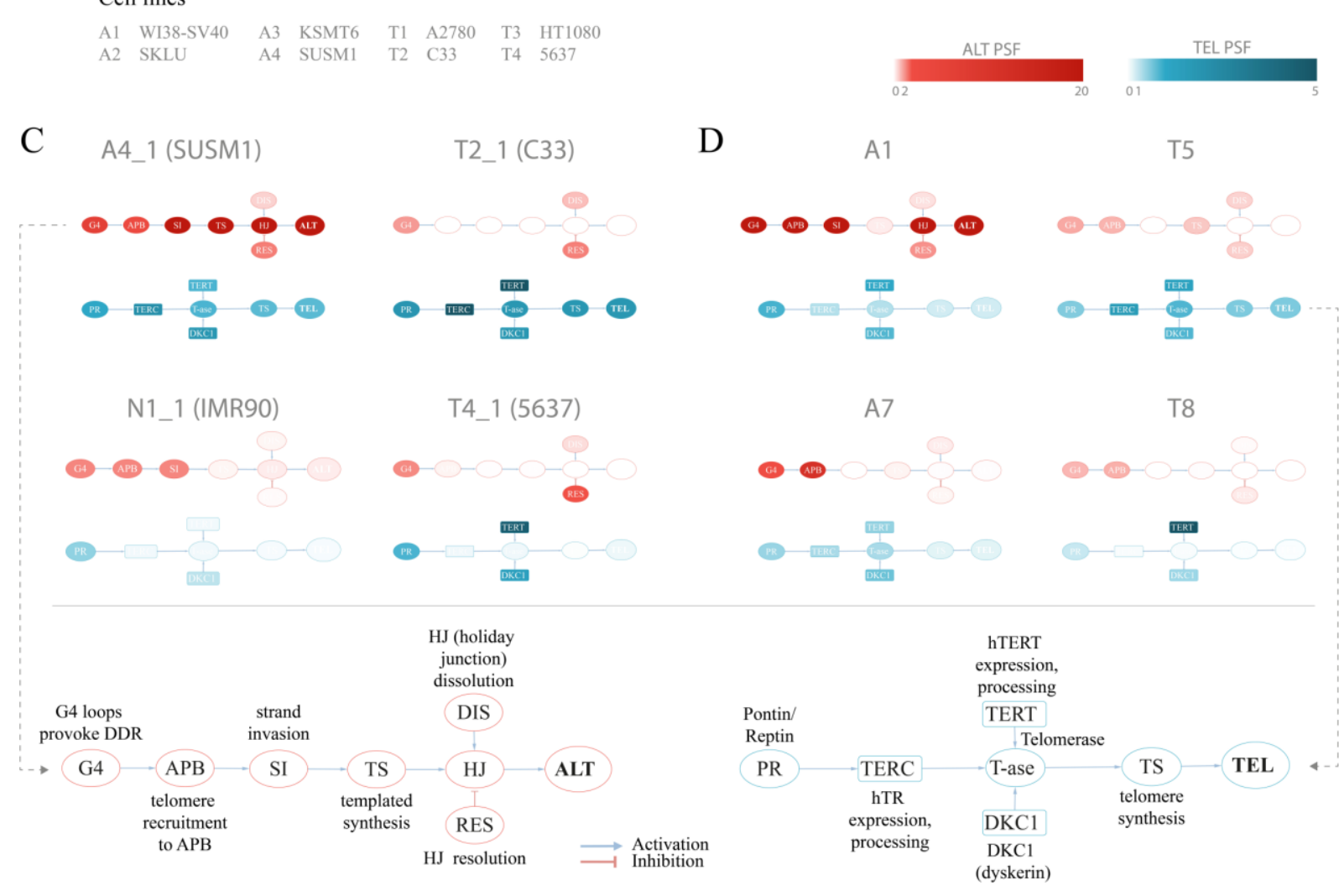

Figure 2. TEL and ALT pathway activity plots for cell lines and liposarcoma tissues.

A. Cell lines and hMSCs plotted according to the TEL PSF ( $\mathrm{x}$ axis) and ALT PSF ( $\mathrm{y}$ axis) values. Color coding corresponds to experimental annotation of TMM states. Horizontal and vertical dash lines separate $\mathrm{ALT}^{+}$from $\mathrm{ALT}^{-}$and $\mathrm{TEL}^{+}$from TEL ${ }^{-}$experimentally annotated samples based on support vector machine classification on the ALT and the TEL PSF values. Technical replicates are distinguished with_1 and _2 suffices. B. Similar representation for liposarcoma tissues and hMSCs. C-D. Examples of pathway activation patterns of some cell lines (C) and liposarcoma tissues (D). PSF values of process nodes are indicated on a light-to-dark color scale. Node abbreviations are explained in the bottom schemes. Pathway activity patterns for all the samples are shown in Supplementary Figures S2 and S3.

Detailed inspection revealed that all double negative samples (green circles) indeed locate in the ALT /TEL' quadrant formed by the perpendicular lines of our classification scheme thus indicating perfect agreement with experimental assays. For single positive $\mathrm{ALT}^{+} / \mathrm{TEL}^{-}$(red) and $\mathrm{ALT}^{-} / \mathrm{TEL}^{+}$(blue) samples one finds their accumulation in the respective top-left and down-right quadrants, 
respectively, as expected. A certain fraction of theses phenotypes is found 'displaced' in the leftdown and top-right quadrants assigning them to double negative and double positive TMM cases, respectively. For some samples, we observed discordance in TMM PSF values between technical replicates, which was also noticeable on the level of gene expression (Supplementary data 2), suggesting possible technical issues during microarray processing. Overall, we obtained $80-85 \%$ agreement between our computational assessment of TMM activity as ALT or TEL single positive and full agreement with double negative samples and the experimental annotations taken from the original publication.

\subsection{Analysis of pathway activation patterns at single gene and single-sample resolution}

For a better understanding of the particular reasons of the diversity observed in the ALT/TEL plots we visualized pathway activity patterns for selected samples in Figure 2C, D by colouring the major event nodes in light-to-dark blue (TEL PSF) or red (ALT PSF) (the nodes were annotated in the part Figure 2C, D; the full gallery of pathway activation patterns for all samples is provided in Supplementary Figures S2 and S3).

SUSM1 (A4), a transformed ALT-activated (according to experimental assignment) cell line derived from fetal liver, shows activation of all the nodes involved in TEL and ALT (Figure 2C), which pushes one replicate to the upper right quadrant corresponding to the double positive $\mathrm{TEL}^{+} / \mathrm{ALT}^{+}$ pathway phenotype. The C33 cell line (T2), derived from cervical squamous cell carcinoma, shows clear activation of the major TEL pathway nodes, while the main ALT events, such as telomere recruitment to APB, strand invasion and telomere synthesis are suppressed, pushing it to the $\mathrm{TEL}^{+} / \mathrm{ALT}^{-}$quadrant in agreement with experimental assignment (Figure 2C). The bladder carcinoma cell line 5637 (T4), experimentally assessed to have high telomerase activity, showed relatively low TEL PSF values. As seen in Figure 2C, the expression and processing of the two telomerase complex subunits hTERT (TEL pathway branch TERT) and dyskerin (branch DKC1) were highly activated in this cell line, however the expression of the factors processing the RNA template hTR was low, thus being a bottleneck for the telomerase complex formation, explaining the observed discrepancy. We could also identify the genes responsible for this, as described in detail below.

Looking at the patterns of the A7 sample in the dataset of liposarcoma tissues (Figure 2D), we observed high activity of the APB branch of the ALT pathway, indicating that both the computational annotation and the experimental assay point on accumulation of APB bodies in this tissue. However, as the expression of downstream factors in the ALT pathway was low (Figure 2D), it compromised the ultimate activation of this pathway. This result supports recent studies showing that the mere presence of APB bodies doesn't necessarily lead to the activation of ALT (Jia-Min Zhang et al., 2019). Similar branch-activation patterns were observed for the A6 and A9 tissue samples (Supplementary Figure S3). It is important to note that these samples had high TEL pathway activity, which is in line with previous observations of high false-positive rate of the APB assay associated with overexpression of TERC or TERT (Henson and Reddel, 2010). In summary, inspection of the PSF patterns along the pathways identifies genes and branches contributing to activation or deactivation of ALT and TEL with single sample resolution. More information regarding gene-level activation patterns can be explored in the full pathway PSF activation patterns (Supplementary data 3).

\subsection{Partial influence (PI) analysis identifies gene-specific triggers of pathway activities}

As a second additional option of extracting gene level information responsible for pathway activation changes we analyzed the partial influence (PI) of each gene (Material and methods section). PI enables understanding of which genes act as triggers to activate or to deactivate selected nodes in the pathways. Genes, increasing or decreasing the PSF of the target node have positive or negative PI's respectively. Activating nodes with log fold change (FC) expression above or below zero in a given sample will thus have a positive or negative PI respectively. Nodes with inhibitory effect, on the other hand, will have the reverse association with PI (Figure 3A).

We have examined the PIs in the TEL pathway of the 5637 (T4) bladder carcinoma cell line (Figure 2A), where branch-level analyses showed suppression of the hTR maturation branch (Figure 
$2 \mathrm{C})$. The results of the PI analysis show that the genes encoding the hTR maturation factors NAFl, WRAP53 and PARN (Figure 3) were responsible for low activity of the hTR branch in this sample. Indeed, bringing the relative expression of $N A F 1$ to a fold change value of 1 (Figure 3B) was sufficient to push the activity of the TEL pathway over the threshold for classifying it as $\mathrm{TEL}^{+}(\log \mathrm{PSF}$ of 0$)$. It is important to mention that the used microarray gene expression datasets did not contain expression values for the TERC gene itself, and only the expression of hTR processing factors contributed to the hTR branch in this case.

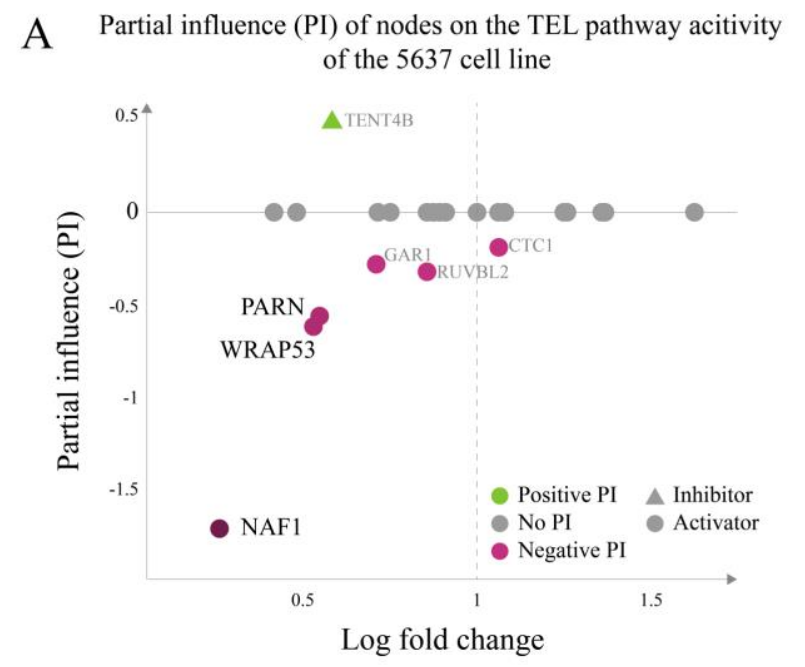

B

Pathway signal flow (PSF) change upon source influence removal
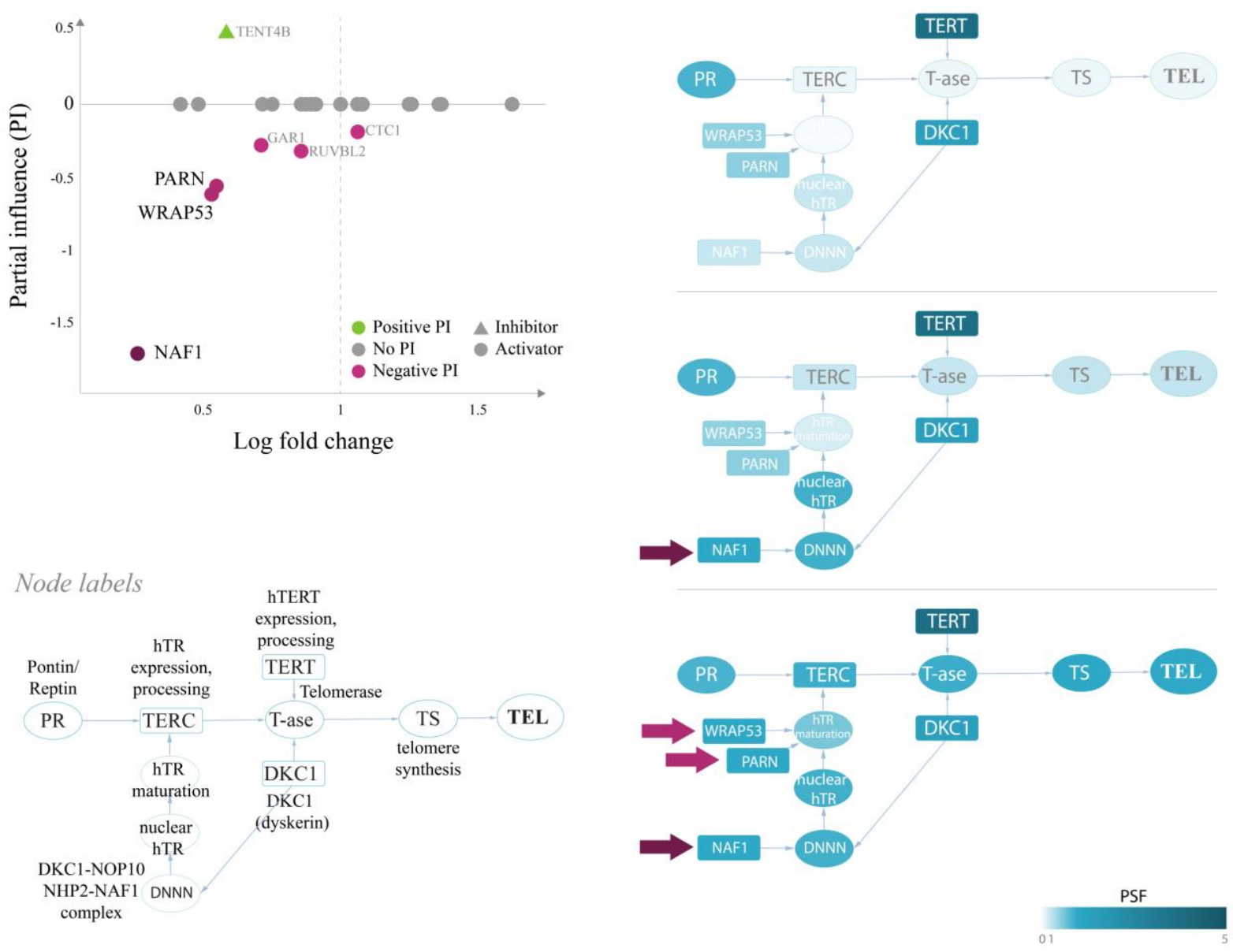

Figure 3. Partial influence of nodes on the TEL pathway activity of the 5637 cell line.

A. Partial influence (PI) of each node is computed as the difference of the TEL node PSF value when the node is set to a fold change (FC) value of 1 . In the first replicate of the 5637 cell line, the genes involved in maturation of the telomerase RNA component hTR (NAF1, WRAP53 and PARN), have the largest negative influence on the TEL pathway activity. Low expression of these genes leads to inactivation of the TERC branch, which is the bottleneck in telomerase complex formation (B). The pathway becomes activated when the influence of NAF1 (C) or NAF1, WRAP53 and PARN (D) is removed by setting their FC to 1 (see Methods).

A similar branch activation and PI pattern was observed for the liposarcoma tissue T8, where the TMM-PSF diverged from the experimental assay results (Figure 2B, Supplementary Figure S6). In the other misclassified sample (T6), we observed high PSF activity of the telomerase complex, however, the low TEL pathway activity was driven by low expression of STN1, which stimulates polymerase alpha in synthesis of the complementary telomeric strand after the action of the telomerase complex (Supplementary Figure S6).

PI analysis also identified that various genes were responsible for activation of the APB branch of the ALT pathway in the A6 and A7 liposarcoma tissues, 
while down-regulation of RAD51 and CHEK1 led to suppression of the downstream strand invasion events leading to low ALT PSF activity in both samples (Supplementary Figure S5). Hence, PI analysis extracts genes which act as triggers for switching TMM on or off with possible impact for altering between ALT and TEL and vice versa.

\subsection{Comparison with TelNet genes}

Our curated TMM-pathway approach considered in total 63 genes extracted from recent publications (see above and Materials and Methods section). As an alternative option we made use of TelNet data base (Braun et al., 2018) which collected 2,094 genes with impact for telomere biology and extracted 336 genes annotated as ALT- or TELassociated (Supplementary Table S3). Separate hierarchical clustering of the expression values of the TEL- and ALT-genes in the cell line and liposarcoma samples analyzed above, well separates double negative $\mathrm{ALT}^{-} / \mathrm{TEL}^{-}$from the single positive ALT and TEL samples on one hand, and also the

cell lines

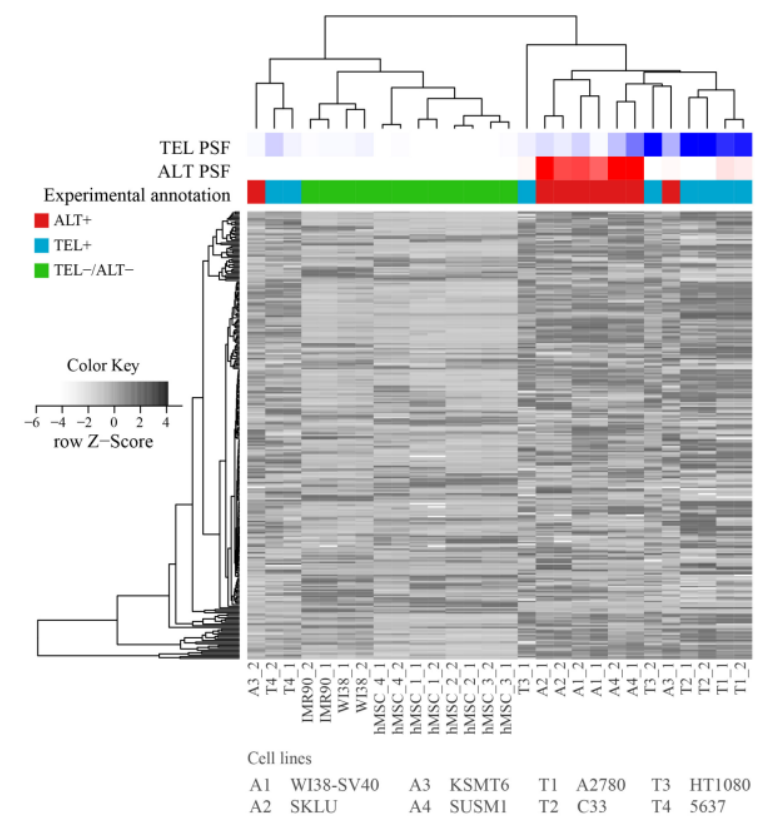

latters each from another. Between $82 \%$ and $85 \%$ of the samples were properly annotated compared with the experimental annotations. Agreement with PSFbased annotations is high (96 and 100\%, respectively). Hence, gene clustering and PSF based classifications and experimental annotations are well-aligned (Figure 4), and those samples that were misclassified by the PSF algorithm were also misclassified with the TelNet gene set clustering. This simple comparison served as an independent validation for the selection of genes in our TMMPSF approach using TelNet. Note that the overlap between both collections is 42 genes, meaning that $67 \%$ of the TMM-pathway genes are considered in TelNet what we attribute to our more recent curation. Moreover, the TMM pathway approach clearly makes use of a markedly reduced number of genes after strict curation and, moreover, enables topology-based analysis not only to extract genes, but also relevant branches and triggers for switching between TMM pathways.

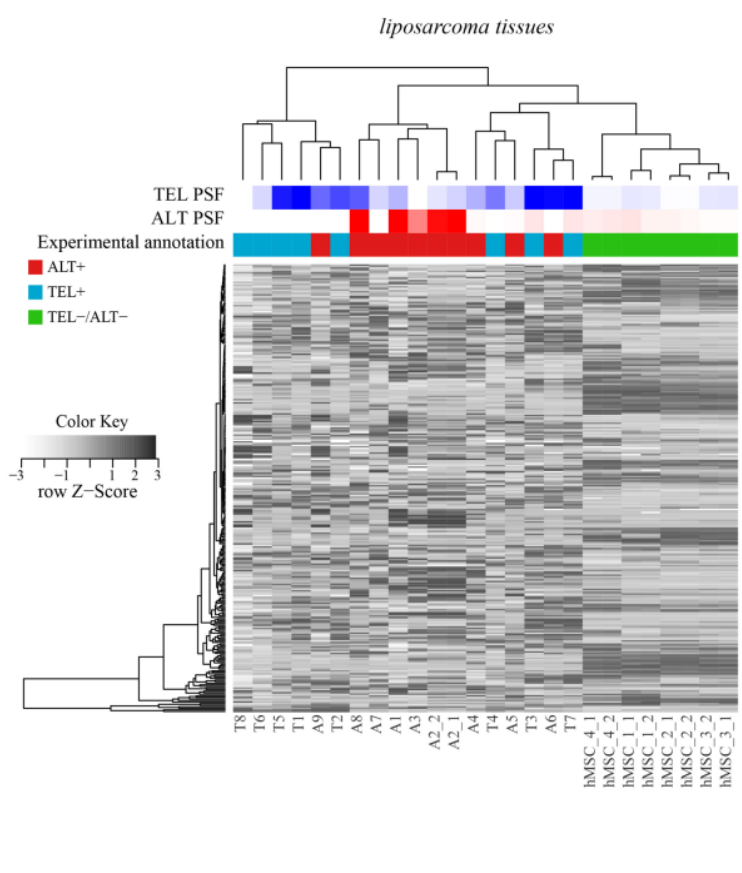

Figure 4. Hierarchical clustering of cell lines and tissues based on expression of genes retrieved from the TelNet database. TEL and ALT PSF values are depicted with blue and red color gradients, and experimental annotations are drawn below. PSF and TelNet assignments closely agree each with another.

\subsection{Telomere maintenance in healthy human tissues}

We have previously applied our PSF approach to study telomere maintenance states in Lynch syndrome and sporadic colorectal cancer subtypes
(Nersisyan et al., 2019). Here we expand this method to evaluate the state of telomere maintenance mechanisms in healthy human tissues.

We estimated TEL and ALT activities in units of PSF across a series of fifteen tissues (overall $\mathrm{N}=$

This is a provisional file, not the final typeset article 
17-80 samples per tissue taken from donors evenly distributed across age and sex groups) making use of RNA-seq data taken from the GTEx portal (Figure 5). The TEL pathway activity was generally low across the tissues (Figure 5A), while ALT shows slightly enhanced PSF-values (Figure 5B).

Interestingly, testis showed considerably increased
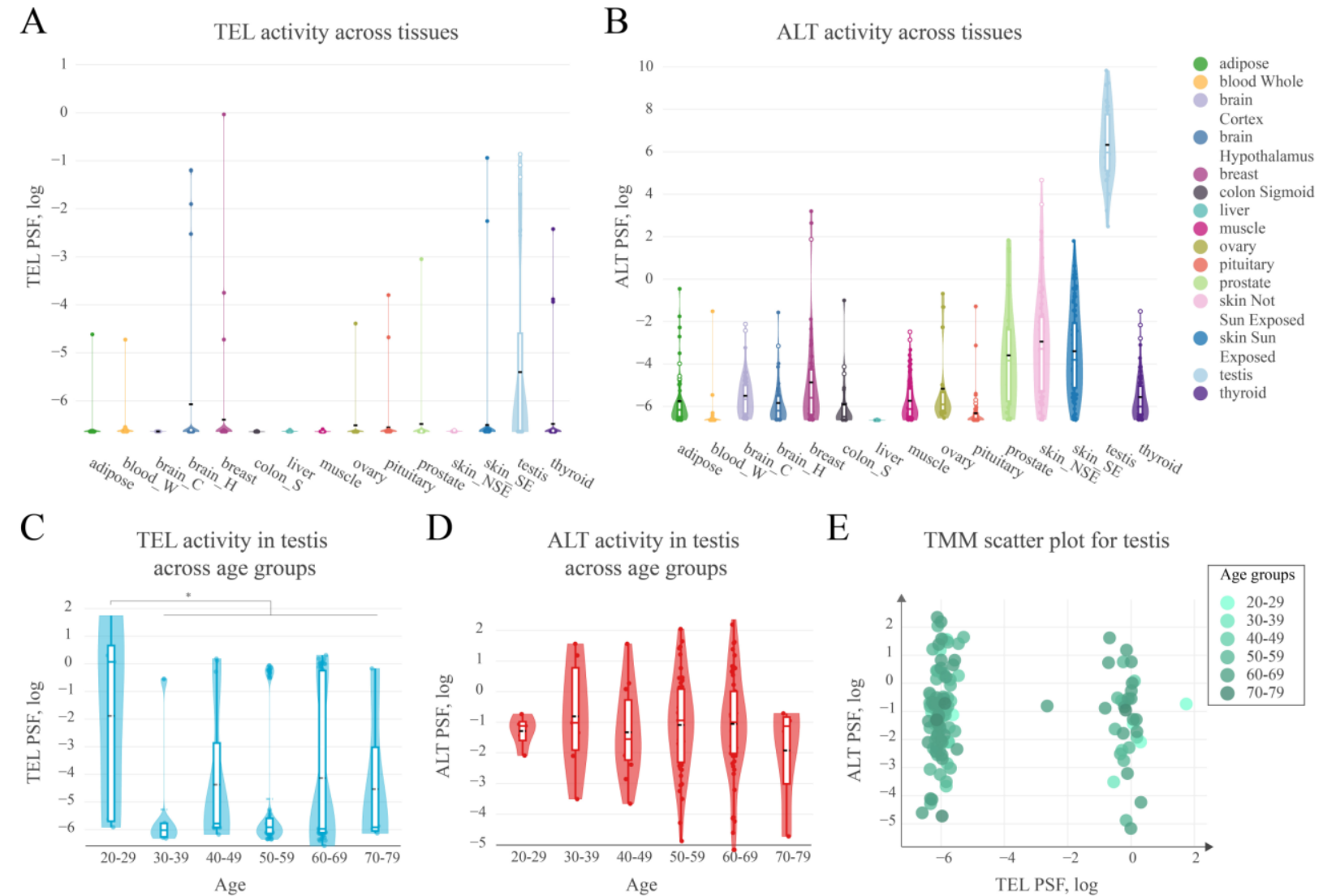

E

TMM scatter plot for testis

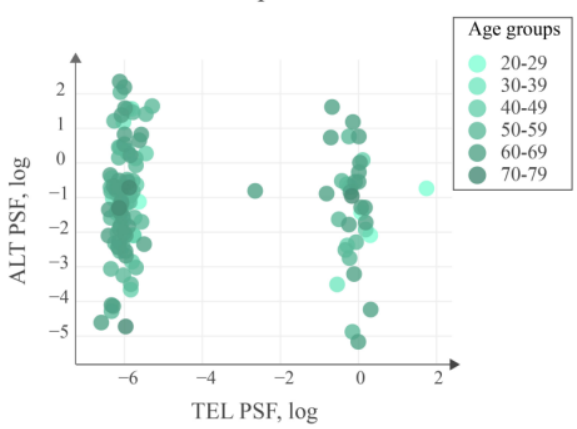

F

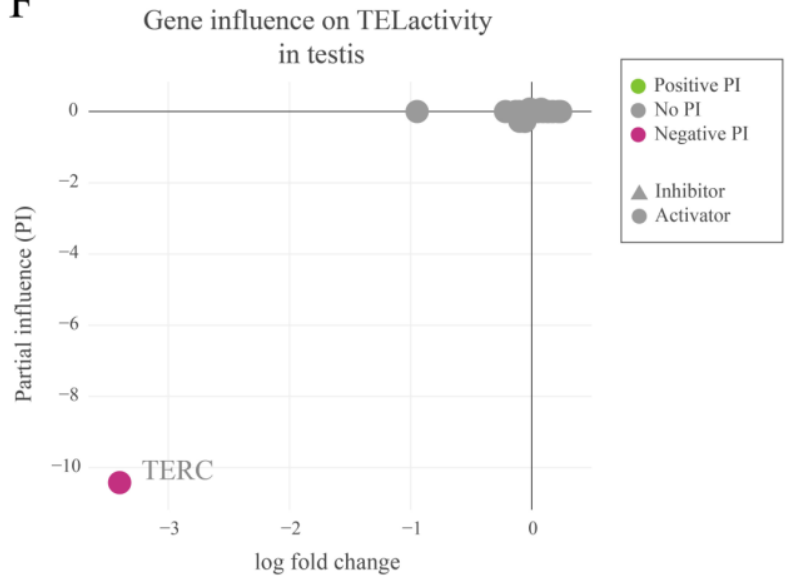

activity of ALT consistently in all of the samples, and also activation of TEL, however, only in half of them, while the other half showed virtually deactivated TEL (Figure $5 \mathrm{~A}, \mathrm{~B}$ ).
G

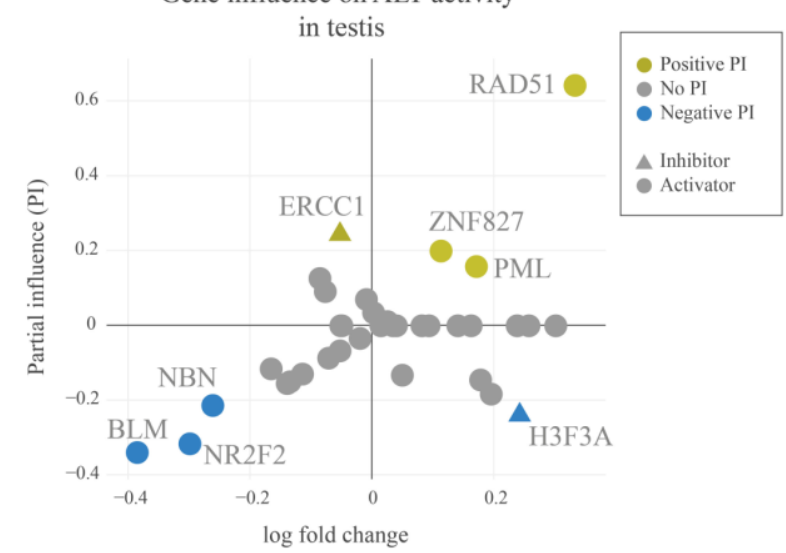

Figure 5. Activity of telomere maintenance mechanisms in healthy human tissues. A. TEL pathway activity in healthy human tissues. The black dashed lines represent means, the colored lines represent medians. B. ALT pathway activity in human tissues. C. TEL pathway activity in testis across age groups. D. ALT pathway activity in testis across age groups. E. ALT and TEL pathway activity scatter-plot in testis colored by age-groups. F. Partial influence (PI) of TEL pathway genes on the pathway activity. G. PI of ALT pathway genes on the pathway activity. 
For a more detailed view on the TMM activation patterns in testis, we stratified the PSF-values of the full sample set $(\mathrm{N}=129)$ according to the age of the donors (Figure $5 \mathrm{C}, \mathrm{D}$ ). No clear ageing-trend of TEL and ALT PSF was observed except a shift of the TEL-PSF distribution towards larger values for younger men of age 20-29 years (Mann-Whitney U test $p=0.01$ ). On the other hand, we observed a clear bi-modal distribution of samples with high or low TEL pathway activities regardless of age (Figure 5 E). The detailed analysis of TEL pathway activation patterns in terms of PI showed that the observed variability was mainly driven by the expression of TERC (Figure 5F). This gene was not expressed in half of the testis samples leading to very low TEL activities. Importantly, TERC was generally found the main limiting factor for TEL pathway activity across all the tissues studied meaning that low TERC expression strongly downscales TEL-PSF. PI analysis of the ALT pathway in testis mainly implicated the importance of RAD51, suggesting RAD51-dependent ALT activation. In the RAD51dependent pathway, telomere-bound POT1 is replaced by RPA, followed by RAD51 recruitment and strand invasion. Low expression of BLM helicase and of the nuclear receptor NR2F2 potentially limits hyperactivity of ALT in this tissue (Conomos et al., 2014; Sobinoff et al., 2017; Zhang et al., 2021), although it has recently be shown that in some cases NR2F2 may not be directly involved in ALT (Alhendi and Royle, 2020). Interestingly, a recent study of Episkopou et al. have identified that the expression of the testis-specific Y-encoded-like protein 5 (TSPYL5), a previously unrecognized APB body component, is crucial for survival of $\mathrm{ALT}^{+}$ cells, as it protects replaced POT1 from proteasomal degradation (Episkopou et al., 2019). We also found high expression of TSPYL5 in our testis samples showing slight correlation with ALT activity (Pearson R = 0.3, Supplementary Figure S7). This supports possible involvement of TSPYL5 in maintaining viability of $\mathrm{ALT}^{+}$cells in healthy human testis.

In summary, our analyses show that both TEL and ALT pathways of telomere maintenance may be activated in human testis. In this tissue, the main driver for ALT pathway activation is RAD51, while the limiting factor for TEL pathway activity is the expression of TERC, which was observed only in a subset of samples, notably more pronounced in younger subjects.

\section{Discussion}

The activation of TMM mechanism can serve as a phenotypic biomarker for prognostic purposes and for choosing chemotherapies, e.g. by direct targeting of the TMM pathways (Villa et al., 2008; Sugarman et al., 2019; Chen et al., 2020). However, little is known about the molecular triggers leading to activation of telomere maintenance mechanisms via the TEL or the ALT pathways. Some cancer tissues are prone to activation of the ALT pathway, such as the mesenchyme-originating liposarcomas, osteosarcomas and glioblastomas, while others are more permissive of TEL activation (Henson et al., 2002). At the same time, some tumors do not activate neither TEL nor ALT TMM pathways, while others may activate both or switch activation from TEL to ALT or vice versa (Costa et al., 2006; Gocha et al., 2013). The molecular mechanisms behind such cellular decisions are mostly unknown. Owing the role of TMM in cancer prognosis and the promise of telomere-targeting therapies (Villa et al., 2008; Sugarman et al., 2019; Chen et al., 2020) it is of paramount importance to investigate these activation patterns, as well as to come up with better approaches to assess or predict TMM states of tissues and individual cells.

Our study aimed at combining information about molecular factors involved in the TMMs to study the mechanisms of activation of either the TEL or the ALT pathways in cancers and healthy human tissues, and to provide a complementary bioinformatics method for identification of TMM phenotypes from gene expression data. To reach this goal, we have reconstructed TEL and ALT pathways of telomere maintenance taking into account, first of all, comprehensive review and recent original articles of the last three years (Supplementary Tables S1, S2). To the best of our knowledge this is the first attempt of providing a holistic view and quantitative analysis of signalling events involved in TMM.

The TMM pathway topologies proved by quantitative assessment of the TEL and ALT TMMs activity in cancer cell lines and tissues based on two gene expression data taken from a previous study (Lafferty-Whyte et al., 2009). Our pathway approach not only considered the expression values of the genes in each pathway, but also their mutual (activating or inhibiting) interactions, complex formation as well as linking operator nodes all 
together potentially influencing the final pathway activity states. According to the combinations of the activity of TEL and ALT we have classified the samples into four TMM phenotypes (TEL $/ \mathrm{ALT}^{-}$, $\mathrm{TEL}^{+} / \mathrm{ALT}^{-}, \mathrm{TEL}^{-} / \mathrm{ALT}^{+}, \mathrm{TEL}^{+} / \mathrm{ALT}^{+}$) in $80-85 \%$ agreement with independent experimental annotations of TMM in the samples. The absence of TERC expression data due to the lack of microarray probes for this gene may have limited the accuracy of the TEL pathway activity estimation in part of the samples.

Our TMM-PSF method stands out with a couple of advantages: (a) it helps to easily annotate samples based on ALT/TEL pathway activity values, and (b) it provides molecular details for dissecting the role of genes and sub-events in the overall activation of the pathway. For example, we could show that for some samples despite their low ALT activity, the APB-pathway branch was highly active, which may explain why these samples were detected as ALT positive in the independent APB assay. This is in agreement with recent studies showing that the existence of APBs does not ensure telomere synthesis and many APBs in the cell may lack ALT activity (Jia-Min Zhang et al., 2019). In consequence APB-based ALT tests may lead to false positives in samples with telomerase overexpression (Henson and Reddel, 2010).

It is important to note that there is no gold-standard method for TMM phenotyping of cells/tissues. All currently available experimental assays have their drawbacks (Pickett and Reddel, 2015; Jia-Min Zhang et al., 2019). The activity of the telomerase enzyme is usually assessed by the TRAP assay that measures the amount of DNA synthesized from a telomere-like template in vitro. However, it has low sensitivity, is not well suited for single-cell analysis and does not account for downstream processes, such as recruitment of the enzyme to the telomeres and synthesis of the complementary strand (Fajkus, 2006). ALT activity is assessed by assays that measure the abundance of extra-telomeric C-circles or of APB's, or heterogeneity of telomere length (Sobinoff and Pickett, 2017). However, while these biomarkers may be common in many ALT positive cells/tissues, it has been shown that they alone are neither sufficient nor required for promoting ALT (Jia-Min Zhang et al., 2019). New methods for direct monitoring of telomere elongation in ALT cells are still being adapted (Verma et al., 2018). There is an urging need for novel assays to detect
TMM states that could help in understanding cellular response to chemotherapies and for development of TMM targeted therapies (Villa et al., 2008; Sugarman et al., 2019; Chen et al., 2020; Recagni et al., 2020). Particularly useful will be assays that allow for TMM assessment in single cells. As it has been shown previously, and confirmed in this study, both TEL and ALT pathway may be co-activated in the same tumor. It will be extremely important to assess this issue by single cell transcriptomics and our pathway approach whether those pathways co-exist in the same cell or show mosaic activation in the tissue (Costa et al., 2006; Gocha et al., 2013). Additionally, switching from TEL to ALT as a cellular response to a therapy is also possible (Gan et al., 2002; Bechter et al., 2004; Shay et al., 2012; Recagni et al., 2020). It is possible that the poorer agreement with experimental assays in the liposarcoma tissue samples, compared with the cell lines, was caused by the presence of different cell types in those tissues. In this sense, using RNA-seq gene expression data to assess TMM activity from single cells is a promising future direction.

We have previously applied our approach to dissect molecular factors involved in TMM activation in Lynch syndrome and sporadic colorectal cancer subtypes in order to study association of ALT with microsatellite and chromosomal instability in those cancers (Nersisyan et al., 2019). Here we expanded beyond these studies to investigate TMM activation patterns in healthy human tissues. The experimental assays have so far been used to detect ALT activity in cancers only. Previous studies using telomeric DNA tagging have found evidence for telomere elongation via the ALT pathway in the absence of high telomerase activity in mammalian somatic tissues during early development (Liu et al., 2007; Neumann et al., 2013) The recent study by Novakovic et al. has identified elevated TERRA levels, elongated telomeres and some evidence for ALT-specific C-circles in human placenta (Novakovic et al., 2016). The authors note, however, that the amount of C-circles was low compared to ALT positive cancers, suggesting that a mild ALT phenotype may exist in specific placental cells. Overall, these studies show that more sensitive methods to detect low ALT levels are needed to further investigate TMM states in healthy human tissues with higher resolution. In this study, gene expression datasets from healthy human tissues from the GTEx portal were used to assess TMM activity 
states. We found high ALT and TEL pathway activities, first of all, in testis. Interestingly, TEL was activated only in a subset of testicular tissues paralleled with marked TERC expression, while depleted TERC levels lead to low TEL phenotypes. Indications for analogous binary mosaicism effects were reported in previous studies. In humans, TERC is mainly expressed in the primary spermatocytes, however at a lower level than in other spermatogenic cells (Paradis et al., 1999). In addition, TERT expression also shows mosaic-like regulation in testis, depending on the cells of the tissue or on the stage of spermatogenesis (Ozturk, 2015). Another study has shown that telomere length increases during the development of male germ cells from spermatogonia to spermatozoa, inversely correlated with enzymatic activity of telomerase (Achi et al., 2000). This could provide the link between the observed TEL mosaicism, and activation of the ALT pathway in testis.

The high ALT activity observed in testis was largely conditioned by upregulation of RAD51, suggesting that the ALT pathway is activated in a RAD51dependent, rather than independent manner in testis (Jia-Min Zhang et al., 2019). Interestingly, the expression of the testis-specific Y-encoded-like protein 5 (TSPYL5), a recently identified APB body component that is crucial for survival of $\mathrm{ALT}^{+}$cells (Episkopou et al., 2019) was associated with ALT activity in healthy human testis in our study. Finally, our results indicate elevated TMM activity in testis in agreement with the recent study, also performed on GTEx datasets. Accordingly, telomeres are the longest in healthy human testis compared with other tissues and are in weak negative correlation with age (Demanelis et al., 2020).

In summary, we have reconstructed the TEL and ALT TMM pathways from previous literature knowledge. It has been carefully curated relying on reported molecular ingredients contributing to TMM and their interactions. Pathway signal flow activity estimates obtained from gene expression data have been shown to reliably estimate the TMM phenotype as a novel complementary approach to experimental assays. The main advantage of our approach is its "white box" (in contrast to "black box") nature meaning that the resulting TMM phenotype can be "dissected" at gene level. In other words, we can explore gene-specific effects on subprocesses or events triggering activation of TMM. The method estimates TEL and ALT pathway activity in the same sample, thus enabling to establish its state in a TEL/ALT continuum with impact for investigating co-activation and switching events between the two pathways, e.g., upon cancer treatment and development. Of importance, owing to its sensitivity, it detects subtle activation of TEL and ALT in healthy human tissues. Despite the actuality of our pathway topologies it is important to note that new studies about additional factors affecting TMMs are permanently appearing with possible consequences for the pathways reconstructed here. Notably, the topologies were reconstructed in a generic manner: as the pathways can be activated via different mechanisms, not all the genes are required for the pathway activation in different situation. Future applications will show what branches and components are important in different situations. Single cell transcriptomics is one important field to essentially improve resolution of our TMM pathway method. Expression based methods thus potentially provide an independent and complementary approach to assess the TMM state. Because of the complex nature of TEL and ALT TMM, single gene expression markers or gene set signatures are potentially insufficient in most cases. Our TMM pathway method paves a new way for omics-based evaluation of TMM with a series of applications ranging from cell experiments to cancer diagnostics.

\section{$4 \quad$ Materials and methods}

\subsection{Literature search and pathway construction}

TEL and ALT pathways presented in this publication were carefully constructed based on comprehensive literature search resulting in 31 publications which provided relevant knowledge about TMM. To find and select publications describing factors involved in the telomere maintenance mechanisms, we searched the PubMed database with terms "telomerase" or "alternative lengthening of telomeres". The first phase was based on "review" articles published before 2020. These reviews provided the order of molecular processes involved in the pathways and thus their basic topology. The TMM genes mentioned in the review articles were chosen and then used in an extended search of the form [gene or protein] AND ("telomerase" OR "alternative lengthening of telomeres"). We also included genes not yet mentioned in review articles, by repeating the initial 
search with "telomerase" or "alternative lengthening of telomeres", concentrating on the original research articles of the last three years (2017-2020).

The articles were read in chronological order and in case of current consensus about the functional role of the mentioned genes they were included in the respective pathway, otherwise they were ignored. To ensure quality, we confirmed each interaction by inter-researcher agreement between the two authors of this manuscript that have curated the pathways. The present version of ALT and TEL pathways (TMMv2.0) is based on a previous version (TMMv1.0) (Nersisyan, 2017; Nersisyan et al., 2019), and makes use of an improved topology, branch and interaction structure according to updated literature knowledge. The network in .xgmml format may be accessed from Supplementary data 4 .

\subsection{Data sources and preprocessing}

For approval of ALT and TEL TMM pathways we made use of gene expression data on cell lines and liposarcoma tissues taken from the study by Lafferty-Whyte et al (Lafferty-Whyte et al., 2009) which were annotated as double negative ALT $^{-}$ /TEL ${ }^{-}$(ALT and TEL inactive) or single positive $\mathrm{ALT}^{+} / \mathrm{TEL}^{-}$(ALT active) or $\mathrm{ALT}^{-} / \mathrm{TEL}^{+}$(TEL active) using independent experiments. The gene expression matrix files were downloaded from the Gene Expression Omnibus (GEO) repository (accession GSE14533). This dataset contains microarray gene expression profiling data for ten cell lines cultured from different tissues, and seventeen liposarcoma tumor samples along with four human Mesenchymal Stem Cells (hMSC) samples isolated from the bone marrow of healthy individuals. ALT activation was assessed by the presence of ALT-associated promyelocytic leukemia bodies (APBs) (Costa et al., 2006; Cairney et al., 2008b), while TEL activation was measured using the telomeric-repeat amplification protocol for telomerase activity detection (TRAP-assay) (Kim et al., 1994; Cairney et al., 2008a). Among the cell lines, four were ALT positive $\left(\mathrm{ALT}^{+} / \mathrm{TEL}^{-}\right)$, four were telomerase positive $\left(\mathrm{ALT}^{-} / \mathrm{TEL}^{+}\right)$, and two were ALT/TEL double inactive (ALT/TEL'). Among the liposarcoma samples, nine were ALT positive and eight were telomerase positive. Most of the samples had two technical replicates. In case of multiple microarray probes mapping to the same gene, the probe with highest standard deviation of values was considered. Cell line and tissue data were processed separately. Gene expression values higher than the 0.9 percentile in each of these sets were limited to that percentile value.

Healthy human tissue RNA-seq gene expression data was obtained from the GTEx portal (release V8) in units of transcripts per million (TPM). Fold changes were computed in comparison to the average of non-zero TPM values per gene. Data of the top 15 most common tissues extracted from subjects suffered violent or fast death from natural causes were selected. They were grouped by age and sex. For cross-tissue analysis we selected a maximum number of 10 subjects per age and sex group). For age-dependent analysis of the testis transcriptome all 129 available testis samples were chosen.

\subsection{Pathway signal flow (PSF) activity and partial influence (PI)}

The pathway signal flow (PSF) algorithm (Arakelyan and Nersisyan, 2013; Nersisyan et al., 2016, 2017) was used to asses TMM pathway activity. It computes the activation along the whole pathway based on relative expression values of its member genes and of their interactions. Details are described in the supplement (section Pathway Signal Flow algorithm and Supplementary Figure S1). The PSF algorithm is implemented in the Cytoscape app PSFC (v1.1.8) (Nersisyan et al., 2017). For the specific tasks applied in this work, we have implemented a higher-level app, TMM (v0.8, http://apps.cytoscape.org/apps/tmm). It compares TMM pathway activation patterns with experimental annotations, uses PSFC for pathway activity computation and it also produces reports for TMM phenotype comparison across samples. The app is written in Java (major version 8), the source code is available at https://github.com/lilit-nersisyan/tmm. The app user guide, along with the example datasets and network files can be accessed at the project homepage http://big.sci.am/software/tmm/.

The partial influence (PI) of a source gene estimates the extent to which its expression affects the activity of a downstream target node in the pathway. The PIvalue depends on the expression value of the source gene, pathway topology and the expression of other pathway members. It is computed by neutralizing the fold change of the gene to $\mathrm{FC}=1$, and calculating the log ratio of PSF at the target node before and after neutralizing its expression 
(Supplementary Figure S4). To compute the mean PI across all the samples in the testis, we have generated a mean sample by averaging fold change values for each gene, and performed PI analyses on it.

\section{Conflict of Interest}

The authors declare that the research was conducted in the absence of any commercial or financial relationships that could be construed as a potential conflict of interest.

\section{Author Contributions}

LN, AA and HB conceived the study. LN and AS performed pathway curation and data analysis. $\mathrm{LN}$ designed the software packages and prepared the figures. All the authors contributed to data interpretation and manuscript preparation.

\section{$7 \quad$ Funding}

No funding information to declare.

\section{Acknowledgments}

The Genotype-Tissue Expression (GTEx) Project was supported by the Common Fund of the Office of the Director of the National Institutes of Health, and by NCI, NHGRI, NHLBI, NIDA, NIMH, and NINDS.

The author(s) acknowledge support from the German Research Foundation (DFG) and Universität Leipzig within the program of Open Access Publishing.

\section{$9 \quad$ References}

Achi, M. V., Ravindranath, N., and Dym, M. (2000). Telomere Length in Male Germ Cells Is Inversely Correlated with Telomerase Activity1. Biol. Reprod. 63, 591-598. doi:10.1095/biolreprod63.2.591.

Alhendi, A. S. N., and Royle, N. J. (2020). The absence of (TCAGGG)n repeats in some telomeres, combined with variable responses to NR2F2 depletion, suggest that this nuclear receptor plays an indirect role in the alternative lengthening of telomeres. Sci. Rep. 10, 20597. doi:10.1038/s41598-020-77606w.

Aragón, L. (2018). The Smc5/6 Complex: New and Old Functions of the Enigmatic Long-Distance Relative. Annu. Rev. Genet. 52, 89-107. doi:10.1146/annurev-genet-120417-031353.

Arakelyan, A., and Nersisyan, L. (2013). KEGGParser: Parsing and editing KEGG pathway maps in Matlab. Bioinformatics 29, 518-519.

Bechter, O. E., Zou, Y., Walker, W., Wright, W. E., and Shay,
J. W. (2004). Telomeric recombination in mismatch repair deficient human colon cancer cells after telomerase inhibition. Cancer Res. 64, 3444-3451. doi:10.1158/0008-5472.CAN-040323.

Blackburn, E. H. (1991). Structure and function of telomeres. Nature 350, 569-73. doi:10.1038/350569a0.

Boyraz, B., Moon, D. H., Segal, M., Muosieyiri, M. Z., Aykanat, A., Tai, A. K., et al. (2016). Posttranscriptional manipulation of TERC reverses molecular hallmarks of telomere disease. J. Clin. Invest. 126, 3377-82. doi:10.1172/JCI87547.

Braun, D. M., Chung, I., Kepper, N., Deeg, K. I., and Rippe, K. (2018). TelNet - a database for human and yeast genes involved in telomere maintenance. BMC Genet. 19, 32. doi:10.1186/s12863-018-0617-8.

Cairney, C. J., Hoare, S. F., Daidone, M.-G., Zaffaroni, N., and Keith, W. N. (2008a). High level of telomerase RNA gene expression is associated with chromatin modification, the ALT phenotype and poor prognosis in liposarcoma. Br. J. Cancer 98, 1467-1474. doi:10.1038/sj.bjc.6604328.

Cairney, C. J., Hoare, S. F., Daidone, M. G., Zaffaroni, N., and Keith, W. N. (2008b). High level of telomerase RNA gene expression is associated with chromatin modification, the ALT phenotype and poor prognosis in liposarcoma. Br. J. Cancer 98, 1467-1474. doi:10.1038/sj.bjc.6604328.

Cayuela, M. L., Flores, J. M., and Blasco, M. A. (2005). The telomerase RNA component Terc is required for the tumourpromoting effects of Tert overexpression. EMBO Rep. 6, 268 274. doi:10.1038/sj.embor.7400359.

Cesare, A. J., and Reddel, R. R. (2008). Telomere uncapping and alternative lengthening of telomeres. Mech. Ageing Dev. 129, 99-108. doi:10.1016/j.mad.2007.11.006.

Chen, L.-Y., Redon, S., and Lingner, J. (2012). The human CST complex is a terminator of telomerase activity. Nature 488 , 540-4. doi:10.1038/nature11269.

Chen, L., Roake, C. M., Freund, A., Batista, P. J., Tian, S., Yin, Y. A., et al. (2018). An Activity Switch in Human Telomerase Based on RNA Conformation and Shaped by TCAB1. Cell 174, 218-230.e13. doi:10.1016/j.cell.2018.04.039.

Chen, X., Tang, W., Shi, J. B., Liu, M. M., and Liu, X. (2020). Therapeutic strategies for targeting telomerase in cancer. Med. Res. Rev. 40, 532-585. doi:10.1002/med.21626.

Cho, N. W., Dilley, R. L., Lampson, M. A., and Greenberg, R. A. (2014). Interchromosomal homology searches drive directional ALT telomere movement and synapsis. Cell 159, 108-121. doi:10.1016/j.cell.2014.08.030.

Chow, T. T., Zhao, Y., Mak, S. S., Shay, J. W., and Wright, W. E. (2012). Early and late steps in telomere overhang processing in normal human cells: The position of the final RNA primer drives telomere shortening. Genes Dev. 26, 1167-1178. doi:10.1101/gad.187211.112. 
Chung, I., Osterwald, S., Deeg, K. I., and Rippe, K. (2012). PML body meets telomere: the beginning of an ALTernate ending? Nucleus 3, 263-75. doi:10.4161/nucl.20326.

Clynes, D., Jelinska, C., Xella, B., Ayyub, H., Scott, C., Mitson, M., et al. (2015). Suppression of the alternative lengthening of telomere pathway by the chromatin remodelling factor ATRX. Nat. Commun. 6, 7538. doi:10.1038/ncomms8538.

Cohen, S. B., Graham, M. E., Lovrecz, G. O., Bache, N., Robinson, P. J., and Reddel, R. R. (2007). Protein composition of catalytically active human telomerase from immortal cells. Science 315, 1850-3. doi:10.1126/science.1138596.

Conomos, D., Reddel, R. R., and Pickett, H. A. (2014). NuRDZNF827 recruitment to telomeres creates a molecular scaffold for homologous recombination. doi:10.1038/nsmb.2877.

Costa, A., Daidone, M. G., Daprai, L., Villa, R., Cantù, S., Pilotti, S., et al. (2006). Telomere maintenance mechanisms in liposarcomas: Association with histologic subtypes and disease progression. Cancer Res. 66, 8918-8924. doi:10.1158/00085472.CAN-06-0273.

Dagg, R. A., Pickett, H. A., Neumann, A. A., Napier, C. E., Henson, J. D., Teber, E. T., et al. (2017). Extensive Proliferation of Human Cancer Cells with Ever-Shorter Telomeres. Cell Rep. 19, 2544-2556. doi:10.1016/j.celrep.2017.05.087.

Deeg, K. I., Chung, I., Bauer, C., and Rippe, K. (2016). Cancer Cells with Alternative Lengthening of Telomeres Do Not Display a General Hypersensitivity to ATR Inhibition. Front. Oncol. 6, 186. doi:10.3389/fonc.2016.00186.

Demanelis, K., Jasmine, F., Chen, L. S., Chernoff, M., Tong, L., Delgado, D., et al. (2020). Determinants of telomere length across human tissues. Science (80-. ). 369. doi:10.1126/SCIENCE.AAZ6876.

Dilley, R. L., Verma, P., Cho, N. W., Winters, H. D., Wondisford, A. R., and Greenberg, R. A. (2016). Break-induced telomere synthesis underlies alternative telomere maintenance. Nature 539, 54-58. doi:10.1038/nature20099.

Dimitrova, N., and de Lange, T. (2009). Cell Cycle-Dependent Role of MRN at Dysfunctional Telomeres: ATM SignalingDependent Induction of Nonhomologous End Joining (NHEJ) in G1 and Resection-Mediated Inhibition of NHEJ in G2. Mol. Cell. Biol. 29, 5552-5563. doi:10.1128/mcb.00476-09.

Dyer, M. A., Qadeer, Z. A., Valle-Garcia, D., and Bernstein, E. (2017). ATRX and DAXX: Mechanisms and Mutations. Cold Spring Harb. Perspect. Med. 7, a026567. doi:10.1101/cshperspect.a026567.

Episkopou, H., Diman, A., Claude, E., Viceconte, N., and Decottignies, A. (2019). TSPYL5 Depletion Induces Specific Death of ALT Cells through USP7-Dependent Proteasomal Degradation of POT1. Mol. Cell 75, 469-482.e6. doi:10.1016/j.molcel.2019.05.027.

Fajkus, J. (2006). Detection of telomerase activity by the TRAP assay and its variants and alternatives. Clin. Chim. Acta 371,

\section{5-31. doi:10.1016/j.cca.2006.02.039.}

Flynn, R. L., Chang, S., and Zou, L. (2012). RPA and POT1: friends or foes at telomeres? Cell Cycle 11, 652-7. doi:10.4161/cc.11.4.19061.

Flynn, R. L., Cox, K. E., Jeitany, M., Wakimoto, H., Bryll, A. R., Ganem, N. J., et al. (2015). Alternative lengthening of telomeres renders cancer cells hypersensitive to ATR inhibitors. Science 347, 273-7. doi:10.1126/science.1257216.

Frohnert, C., Hutten, S., Wälde, S., Nath, A., and Kehlenbach, R. H. (2014). Importin 7 and Nup358 promote nuclear import of the protein component of human telomerase. PLoS One 9. doi:10.1371/journal.pone.0088887.

Gan, Y., Mo, Y., Johnston, J., Lu, J., Wientjes, M. G., and Au, J. L.-S. (2002). Telomere maintenance in telomerase-positive human ovarian SKOV-3 cells cannot be retarded by complete inhibition of telomerase. FEBS Lett. 527, 10-14. doi:10.1016/S0014-5793(02)03141-1.

Gocha, A. R. S., Nuovo, G., Iwenofu, O. H., and Groden, J. (2013). Human sarcomas are mosaic for telomerase-dependent and telomerase- independent telomere maintenance mechanisms: Implications for telomere-based therapies. Am. J. Pathol. 182, 41-48. doi:10.1016/j.ajpath.2012.10.001.

Greenberg, R. a (2005). Telomeres, crisis and cancer. Curr. Mol. Med. 5, 213-8. doi:10.2174/1566524053586590.

Hakobyan, A., Nersisyan, L., and Arakelyan, A. (2016). Quantitative trait association study for mean telomere length in the South Asian genomes. Bioinformatics 32, 1697-700. doi:10.1093/bioinformatics/btw027.

Henson, J. D., Neumann, A. A., Yeager, T. R., and Reddel, R. R. (2002). Alternative lengthening of telomeres in mammalian cells. Oncogene 21, 598-610. doi:10.1038/sj.onc.1205058.

Henson, J. D., and Reddel, R. R. (2010). Assaying and investigating Alternative Lengthening of Telomeres activity in human cells and cancers. FEBS Lett. 584, 3800-3811. doi:10.1016/j.febslet.2010.06.009.

Hug, N., and Lingner, J. (2006). Telomere length homeostasis. Chromosoma 115, 413-425. doi:10.1007/s00412-006-0067-3.

Jeong, S. A., Kim, K., Lee, J. H., Cha, J. S., Khadka, P., Cho, H. S., et al. (2015). Akt-mediated phosphorylation increases the binding affinity of hTERT for importin $\alpha$ to promote nuclear translocation. J. Cell Sci. doi:10.1242/jcs.166132.

Jia-Min Zhang, A., Yadav, T., Ouyang, J., Lan, L., and Zou Correspondence, L. (2019). Alternative Lengthening of Telomeres through Two Distinct Break-Induced Replication Pathways. CellReports 26, 955-968.e3. doi:10.1016/j.celrep.2018.12.102.

Jiang, W.-Q., Zhong, Z.-H., Henson, J. D., Neumann, A. A., Chang, A. C.-M., and Reddel, R. R. (2005). Suppression of Alternative Lengthening of Telomeres by Sp100-Mediated Sequestration of the MRE11/RAD50/NBS1 Complex. Mol. 
Cell. Biol. 25, 2708-2721. doi:10.1128/MCB.25.7.27082721.2005.

Kim, N. W., Piatyszek, M. A., Prowse, K. R., Harley, C. B., West, M. D., Ho, P. L. C., et al. (1994). Specific association of human telomerase activity with immortal cells and cancer. Science (80-. ). 266, 2011-2015. doi:10.1126/science.7605428.

Lafferty-Whyte, K., Cairney, C. J., Will, M. B., Serakinci, N., Daidone, M.-G., Zaffaroni, N., et al. (2009). A gene expression signature classifying telomerase and ALT immortalization reveals an hTERT regulatory network and suggests a mesenchymal stem cell origin for ALT. Oncogene 28, 3765-74. doi:10.1038/onc.2009.238.

Lafrance-Vanasse, J., Williams, G. J., and Tainer, J. A. (2015). Envisioning the dynamics and flexibility of Mre11-Rad50-Nbs1 complex to decipher its roles in DNA replication and repair. Prog. Biophys. Mol. Biol. 117, 182-193. doi:10.1016/j.pbiomolbio.2014.12.004.

Lee, J. H., Khadka, P., Baek, S. H., and Chung, I. K. (2010). CHIP promotes hTERT degradation and negatively regulates telomerase activity. J. Biol. Chem. 285, 42033-42045. doi:10.1074/jbc.M110.149831.

Liu, L., Bailey, S. M., Okuka, M., Muñoz, P., Li, C., Zhou, L., et al. (2007). Telomere lengthening early in development. Nat. Cell Biol. 9, 1436-1441. doi:10.1038/ncb1664.

Lovejoy, C. A., Li, W., Reisenweber, S., Thongthip, S., Bruno, J., de Lange, T., et al. (2012). Loss of ATRX, genome instability, and an altered DNA damage response are hallmarks of the alternative lengthening of telomeres pathway. PLoS Genet. 8, e1002772. doi:10.1371/journal.pgen.1002772.

Martínez, P., and Blasco, M. A. (2015). Replicating through telomeres: a means to an end. Trends Biochem. Sci. 40, 504-15. doi:10.1016/j.tibs.2015.06.003.

Min, J., Wright, W. E., and Shay, J. W. (2019). Clustered telomeres in phase-separated nuclear condensates engage mitotic DNA synthesis through BLM and RAD52. Genes Dev. 33, 814-827. doi:10.1101/gad.324905.119.

Moon, D. H., Segal, M., Boyraz, B., Guinan, E., Hofmann, I., Cahan, P., et al. (2015). Poly(A)-specific ribonuclease (PARN) mediates 3'-end maturation of the telomerase RNA component. Nat. Genet. 47, 1482-1488. doi:10.1038/ng.3423.

Nersisyan, L. (2017). Telomere Analysis Based on HighThroughput Multi -Omics Data. Available at: urn:nbn:de:bsz:15-qucosa2-162974.

Nersisyan, L., Hopp, L., Loeffler-Wirth, H., Galle, J., Loeffler, M., Arakelyan, A., et al. (2019). Telomere Length Maintenance and Its Transcriptional Regulation in Lynch Syndrome and Sporadic Colorectal Carcinoma. Front. Oncol. 9.

Nersisyan, L., Johnson, G., Riel-Mehan, M., Pico, A. R., and Arakelyan, A. (2017). PSFC: a Pathway Signal Flow Calculator App for Cytoscape [version 2; peer review: 2 approved]. F1000Research 4. doi:10.12688/f1000research.6706.2.
Nersisyan, L., Löffler-Wirth, H., Arakelyan, A., and Binder, H. (2016). Gene Set- and Pathway- Centered Knowledge Discovery Assigns Transcriptional Activation Patterns in Brain, Blood, and Colon Cancer: A Bioinformatics Perspective. Int. J. Knowl. Discov. Bioinforma. 4, 24. doi:10.4018/IJKDB.2014070104.

Neumann, A. A., Watson, C. M., Noble, J. R., Pickett, H. A., Tam, P. P. L., and Reddel, R. R. (2013). Alternative lengthening of telomeres in normal mammalian somatic cells. Genes Dev. 27, 18-23. doi:10.1101/gad.205062.112.

Novakovic, B., Napier, C. E., Vryer, R., Dimitriadis, E., Manuelpillai, U., Sharkey, A., et al. (2016). DNA methylation mediated up-regulation of TERRA non-coding RNA is coincident with elongated telomeres in the human placenta. Mol. Hum. Reprod. 22, 791-799. doi:10.1093/molehr/gaw053.

Ozturk, S. (2015). Telomerase activity and telomere length in male germ cells. Biol. Reprod. 92, 53-54. doi:10.1095/biolreprod.114.124008.

Paradis, V., Dargère, D., Laurendeau, I., Benoît, G., Vidaud, M., Jardin, A., et al. (1999). Expression of the RNA component of human telomerase (hTR) in prostate cancer, prostatic intraepithelial neoplasia, and normal prostate tissue. J. Pathol. 189, 213-218. doi:10.1002/(SICI)1096-

9896(199910)189:2<213::AID-PATH417>3.0.CO;2-A.

Pickett, H. A., and Reddel, R. R. (2015). Molecular mechanisms of activity and derepression of alternative lengthening of telomeres. Nat. Struct. Mol. Biol. 22, 875-880.

doi:10.1038/nsmb.3106.

Potts, P. R., and Yu, H. (2007). The SMC5/6 complex maintains telomere length in ALT cancer cells through SUMOylation of telomere-binding proteins. Nat. Struct. Mol. Biol. 14, 581-90. doi:10.1038/nsmb1259.

Recagni, M., Bidzinska, J., Zaffaroni, N., and Folini, M. (2020). The Role of Alternative Lengthening of Telomeres Mechanism in Cancer: Translational and Therapeutic Implications. Cancers (Basel). 12, 949. doi:10.3390/cancers12040949.

Rice, C., and Skordalakes, E. (2016). Structure and function of the telomeric CST complex. Comput. Struct. Biotechnol. J. 14, 161-7. doi:10.1016/j.csbj.2016.04.002.

Schmidt, J. C., and Cech, T. R. (2015). Human telomerase: Biogenesis, trafficking, recruitment, and activation. Genes Dev. 29, 1095-1105. doi:10.1101/gad.263863.115.

Shay, J. W. (2016). Role of Telomeres and Telomerase in Aging and Cancer. Cancer Discov. 6, 584-593. doi:10.1158/21598290.CD-16-0062.

Shay, J. W., Reddel, R. R., and Wright, W. E. (2012). Cancer: Cancer and telomeres - An alternative to telomerase. Science (80-. ). doi:10.1126/science.1222394.

Sobinoff, A. P., Allen, J. A., Neumann, A. A., Yang, S. F., Walsh, M. E., Henson, J. D., et al. (2017). BLM and SLX4 play opposing roles in recombination-dependent replication at human 
telomeres. EMBO J. 36, 2907-2919.

doi:10.15252/embj.201796889.

Sobinoff, A. P., and Pickett, H. A. (2017). Alternative Lengthening of Telomeres: DNA Repair Pathways Converge. Trends Genet. 33, 921-932. doi:10.1016/J.TIG.2017.09.003.

Sobinoff, A. P., and Pickett, H. A. (2020). Mechanisms that drive telomere maintenance and recombination in human cancers. Curr. Opin. Genet. Dev. 60, 25-30. doi:10.1016/j.gde.2020.02.006.

Sugarman, E. T., Zhang, G., and Shay, J. W. (2019). In perspective: An update on telomere targeting in cancer. Mol. Carcinog. 58, 1581-1588. doi:10.1002/mc.23035.

Tseng, C.-K., Wang, H.-F., Burns, A. M., Schroeder, M. R., Gaspari, M., and Baumann, P. (2015). Human Telomerase RNA Processing and Quality Control. Cell Rep. 13, 2232-2243. doi:10.1016/j.celrep.2015.10.075.

Venteicher, A. S., Meng, Z., Mason, P. J., Veenstra, T. D., and Artandi, S. E. (2008). Identification of ATPases Pontin and Reptin as Telomerase Components Essential for Holoenzyme Assembly. Cell 132, 945-957. doi:10.1016/j.cell.2008.01.019.
Verma, P., Dilley, R. L., Gyparaki, M. T., and Greenberg, R. A. (2018). "Direct Quantitative Monitoring of Homology-Directed DNA Repair of Damaged Telomeres," in Methods in Enzymology doi:10.1016/bs.mie.2017.11.010.

Villa, R., Daidone, M. G., Motta, R., Venturini, L., De Marco, C., Vannelli, A., et al. (2008). Multiple mechanisms of telomere maintenance exist and differentially affect clinical outcome in diffuse malignant peritoneal mesothelioma. Clin. Cancer Res. 14, 4134-4140. doi:10.1158/1078-0432.CCR-08-0099.

Yuan, X., Larsson, C., and Xu, D. (2019). Mechanisms underlying the activation of TERT transcription and telomerase activity in human cancer: old actors and new players. Oncogene 38, 6172-6183. doi:10.1038/s41388-019-0872-9.

Zhang, J.-M., Genois, M.-M., Ouyang, J., Lan, L., and Zou, L. (2021). Alternative lengthening of telomeres is a selfperpetuating process in ALT-associated PML bodies. Mol. Cell. doi:10.1016/j.molcel.2020.12.030.

Zhu, X. D., Niedernhofer, L., Kuster, B., Mann, M., Hoeijmakers, J. H. J., and De Lange, T. (2003). ERCC1/XPF Removes the 3' Overhang from Uncapped Telomeres and Represses Formation of Telomeric DNA-Containing Double Minute Chromosomes. Mol. Cell. doi:10.1016/S10972765(03)00478-7.

\section{Tables}

10.1 Table 1. The ALT pathway nodes with activating (+) or inhibiting (-) effects.

Name (alias) Effect Reference G4 formation; DDR provokation H3F3A

\begin{tabular}{cc}
\hline ATRX/DAXX & - \\
\hline DAXX & - \\
\hline
\end{tabular}

(Dyer et al., 2017) (Lovejoy et al., 2012)

ATRX

(Clynes et al., 2015)

Telomere bridge formation (NTB)

\begin{tabular}{|c|c|c|}
\hline NR2C2 (TRF4) & + & \multirow{4}{*}{ (Conomos et al., 2014) } \\
\hline NR2F2 (COUP-TF2) & + & \\
\hline ZNF827 & + & \\
\hline NuRD complex & + & \\
\hline \multicolumn{3}{|c|}{ Recruitment of telomeres to APBs (APB) } \\
\hline PML & + & (Chung et al., 2012) \\
\hline SMC5/6 complex & + & \multirow{4}{*}{$\begin{array}{c}\text { (Aragón, 2018) } \\
\text { (Potts and Yu, 2007) }\end{array}$} \\
\hline SMC5 (RAD18) & + & \\
\hline SMC6 (Spr18) & + & \\
\hline NSMCE2 (NSE2) & + & \\
\hline
\end{tabular}

\begin{tabular}{|c|c|c|}
\hline \multicolumn{3}{|c|}{ Strand invastion (SI) } \\
\hline POT1 & - & \multirow{3}{*}{ (Flynn et al., 2012) } \\
\hline RPA & + & \\
\hline RPA1 & + & \\
\hline
\end{tabular}

Name (alias) Effect Reference Template directed synthesis

\begin{tabular}{|c|c|c|}
\hline POLD3 & + & \multirow{3}{*}{ (Dilley et al., 2016) } \\
\hline PCNA & + & \\
\hline RFC1 & + & \\
\hline \multicolumn{3}{|c|}{$\begin{array}{l}\text { Holiday Junction (HJ) processing (HJ } \\
\text { dissolution) }\end{array}$} \\
\hline MRN complex & + & $\begin{array}{l}\text { (Dimitrova and de } \\
\text { Lange, 2009) } \\
\text { (Clynes et al., 2015) }\end{array}$ \\
\hline MRE11 & + & \multirow{3}{*}{$\begin{array}{c}\text { (Lafrance-Vanasse et al., } \\
\text { 2015) }\end{array}$} \\
\hline RAD50 & + & \\
\hline NBS1 & + & \\
\hline SP100 & - & (Jiang et al., 2005) \\
\hline BTR complex & + & $\begin{array}{l}\text { (Sobinoff et al., 2017) } \\
\text { (Min et al., 2019) }\end{array}$ \\
\hline BLM & + & \multirow{4}{*}{ (Sobinoff et al., 2017) } \\
\hline TOP3A & + & \\
\hline RMI1 & + & \\
\hline RMI2 & + & \\
\hline \multicolumn{3}{|c|}{$\begin{array}{l}\text { Holiday Junction }(\mathrm{HJ}) \text { processing }(\mathrm{HJ} \\
\text { resolution }\end{array}$} \\
\hline
\end{tabular}

SLX4-SLX1ERRC4 complex

\begin{tabular}{cc}
\hline SLX1 & $=$ \\
\hline SLX4 & $=$ \\
\hline SLX1A & $=$
\end{tabular}




\begin{tabular}{|c|c|c|}
\hline RPA2 & + & \\
\hline RPA3 & + & \\
\hline HNRNPA1 & - & \\
\hline ATR & + & $\begin{array}{l}\text { (Flynn et al., 2012) (Flynn } \\
\text { et al., 2015) (Deeg et al., } \\
\text { 2016) (Dilley et al., 2016) }\end{array}$ \\
\hline CHEK1 & + & (Dilley et al., 2016) \\
\hline RAD51 & + & \multirow{3}{*}{$\begin{array}{l}\text { (Cho et al., 2014) } \\
\text { (Jia-Min Zhang et al., } \\
\text { 2019) }\end{array}$} \\
\hline HOP2 & + & \\
\hline MND1 & + & \\
\hline RAD52 & + & $\begin{array}{c}\text { (Jia-Min Zhang et al., } \\
\text { 2019) } \\
\text { (Min et al., 2019) }\end{array}$ \\
\hline
\end{tabular}

\begin{tabular}{ccc} 
SLX1B & - & \\
\hline ERCC1 & - & (Zhu et al., 2003)
\end{tabular}

10.2 Table 2. The TEL pathway nodes with activating (+) or inhibiting (-) effects.

\begin{tabular}{|c|c|c|c|c|c|}
\hline Name (alias) & Effect & Reference & Name (alias) & Effect & Reference \\
\hline \multicolumn{3}{|c|}{$\begin{array}{l}\text { Nuclear TERT (TERT activation and } \\
\text { recruitment) }\end{array}$} & \multicolumn{3}{|c|}{ Telomerase assembly } \\
\hline TERT & + & (Cohen et al., 2007) & TERT & + & (Cohen et al., 2007) \\
\hline KPNA1 & + & \multirow{2}{*}{ (Jeong et al., 2015) } & TERC & + & $\begin{array}{l}\text { (Cohen et al., 2007)(Cayuela et } \\
\text { al., 2005) }\end{array}$ \\
\hline RAN & + & & DKC1 & + & (Schmidt and Cech, 2015) \\
\hline IPO7 & + & \multirow[b]{2}{*}{ (Frohnert et al., 2014) } & Pontin/Reptin & + & \multirow{3}{*}{ (Venteicher et al., 2008) } \\
\hline RANBP2 & + & & RUVBL1 & + & \\
\hline HSP90 & + & & RUVBL2 & + & \\
\hline HSP90AA1 & + & & \multicolumn{3}{|c|}{ Recruitment to telomeres and synthesis } \\
\hline HSP90AA1 & + & & CST complex & + & \\
\hline HSP90AB1 & + & & CTC1 & + & \\
\hline PTGES3 & + & (Jeong et al., 2015) & STN1 & + & \\
\hline STUB1 & - & (Lee et al., 2010) & TEN1 & + & (Chen et al., 2012) \\
\hline \multicolumn{3}{|c|}{ hTR maturation } & & & \\
\hline TERC & + & $\begin{array}{l}\text { (Cohen et al., 2007) } \\
\text { (Cayuela et al., 2005) }\end{array}$ & & & \\
\hline PARN & + & $\begin{array}{l}\text { (Moon et al., 2015) } \\
\text { (Boyraz et al., 2016) }\end{array}$ & & & \\
\hline TRAMP & - & (Boyraz et al., 2016) & & & \\
\hline TENT4B (PAPD5) & - & $\begin{array}{l}\text { (Tseng et al., 2015) } \\
\text { (Moon et al., 2015) }\end{array}$ & & & \\
\hline MTREX (MTR4) & - & & & & \\
\hline AIR2 (ZCCHC7) & - & (Tseng et al., 2015) & & & \\
\hline $\begin{array}{l}\text { DKC1-NOP10- } \\
\text { NHP2-NAF1 }\end{array}$ & + & \multirow{6}{*}{$\begin{array}{l}\text { (Schmidt and Cech, } \\
\text { 2015) }\end{array}$} & & & \\
\hline DKC1 & + & & & & \\
\hline NOP10 & + & & & & \\
\hline NHP2 & + & & & & \\
\hline NAF1 & + & & & & \\
\hline GAR1 & + & & & & \\
\hline WRAP53 & + & (Chen et al., 2018) & & & \\
\hline
\end{tabular}

This is a provisional file, not the final typeset article 


\section{Supplementary data 1}

Table S3. Functional role of the ALT pathway nodes.

\begin{tabular}{|c|c|c|c|c|}
\hline Name (alias) & Type $^{\mathbf{a}}$ & Description & Effect $^{\text {b }}$ & Reference \\
\hline \multicolumn{5}{|c|}{ G4 formation; DDR provokation } \\
\hline \multicolumn{5}{|c|}{$\begin{array}{c}\text { G4 quadruplexes are telomeric structures that serve as replication fork barriers and may trigger DNA damage } \\
\text { response (DDR) that may in turn recruit ALT factors. }\end{array}$} \\
\hline $\mathrm{H} 3 \mathrm{~F} 3 \mathrm{~A}$ & G & $\begin{array}{l}\text { H3.3 histone variant. Suppresses formation of G4 structures at } \\
\text { telomeres, which are replication fork barriers at telomeres, trigger fork } \\
\text { stalling and restart by homology directed repair, and are HR substrates. } \\
\text { The purpose of H3.3 deposition at telomeres remains unclear. }\end{array}$ & - & $\begin{array}{l}\text { (Clynes et al., 2015), } \\
\text { (Dyer et al., 2017) }\end{array}$ \\
\hline DAXX-ATRX & $\mathrm{C}$ & $\begin{array}{l}\text { ATRX/DAXX complex is required for deposition of H3.3 histone } \\
\text { variants at telomeres. }\end{array}$ & - & (Dyer et al., 2017) \\
\hline DAXX & G & $\begin{array}{l}\text { Member of ATRX/DAXX. Histone chaperone. Binds H3.3 and } \\
\text { deposits H3.3-H4 tetramers onto naked DNA. 80\% of ALT tumors } \\
\text { show mutations in ATRX/DAXX. }\end{array}$ & - & $\begin{array}{l}\text { (Dyer et al., 2017), } \\
\text { (Lovejoy et al., 2012) }\end{array}$ \\
\hline ATRX & G & $\begin{array}{l}\text { Member of ATRX/DAXX. Chromatin remodelling factor. Binds } \\
\text { DAXX to incorporate H3.3 to telomeres. 80\% of ALT tumors show } \\
\text { mutations in ATRX/DAXX. Re-introduction of ATRX represses ALT. }\end{array}$ & - & $\begin{array}{l}\text { (Dyer et al., 2017), } \\
\text { (Lovejoy et al., 2012), } \\
\text { (Clynes et al., 2015) }\end{array}$ \\
\hline \multicolumn{5}{|c|}{ NuRD-mediated telomere bridge formation (NTB) } \\
\hline \multicolumn{5}{|c|}{$\begin{array}{c}\text { Telomeric bridges are molecular structures that bring together two telomeric strands (chromosomes) as an } \\
\text { initial step before strand invasion. }\end{array}$} \\
\hline NR2C2 (TR4) & G & $\begin{array}{l}\text { Nuclear receptor. Gets recruited to ALT telomeres. In turn, recruits } \\
\text { ZNF827. }\end{array}$ & + & \multirow{4}{*}{ (Conomos et al., 2014) } \\
\hline NR2F2 (COUP-TF2) & G & $\begin{array}{l}\text { Nuclear receptor. Gets recruited to ALT telomeres. In turn, recruits } \\
\text { ZNF827. }\end{array}$ & + & \\
\hline ZNF827 & G & $\begin{array}{l}\text { Zinc finger protein. Is recruited to ALT telomeres via NR2C2 and } \\
\text { NR2F2. In turn, recruits NuRD complex. }\end{array}$ & + & \\
\hline NuRD & $\mathrm{C}$ & $\begin{array}{l}\text { Chromatin remodeling complex. Is recruited to ALT telomeres by } \\
\text { ZNF827. Serves as a bridge between two telomeric strands, and } \\
\text { between telomeres and APB. }\end{array}$ & + & \\
\hline \multicolumn{5}{|c|}{ Recruitment of telomeres to APBs (APB) } \\
\hline \multicolumn{5}{|c|}{ Formation of $A P B s$ and recruitment of telomeres to APB sites. } \\
\hline PML & G & Transcription factor. One of the main consituents of APBs. & + & (Chung et al., 2012) \\
\hline SMC5/6 & $\mathrm{C}$ & $\begin{array}{l}\text { A structural maintenance of chromosomes (SMC) complex. } \\
\text { NSE2(member)-mediated SUMOylation of shelterin proteins is } \\
\text { required for recruitment of telomeres to APBs, as PML has a SUMO- } \\
\text { binding pocket. Knock-down of SMC5, SMC6 and NSE2 reduces ALT } \\
\text { activity. }\end{array}$ & + & \multirow{4}{*}{$\begin{array}{l}\text { (Aragón, 2018), (Potts and } \\
\text { Yu, 2007) }\end{array}$} \\
\hline SMC5 (RAD18) & G & Member of SMC5/6. & + & \\
\hline SMC6 (Spr18) & G & Member of SMC5/6. & + & \\
\hline NSMCE2 (NSE2) & $\mathrm{G}$ & $\begin{array}{l}\text { Member of SMC5/6. NSE2-mediated SUMOylation of shelterin } \\
\text { proteins is required for recruitment of telomeres to APBs. }\end{array}$ & + & \\
\hline
\end{tabular}

Strand invastion (SI)

The release and subsequent hybridization of 3' strand of one telomere to 5' strand of another telomere or telomeric template.

\begin{tabular}{|c|c|c|c|c|}
\hline POT1 & G & $\begin{array}{l}\text { Member of shelterin complex, binds ssDNA at telomeres. Antagonizes } \\
\text { the binding of RPA to telomeres. }\end{array}$ & - & \\
\hline RPA & I & $\begin{array}{l}\text { A non-sequence specific ssDNA binding complex of RPA1, RPA2 and } \\
\text { RPA3. Replaces POT1 and recruits ATR to ssDNA at telomeres. }\end{array}$ & + & \\
\hline RPA1 & G & Member of RPA complex. & + & \\
\hline RPA2 & G & Member of RPA complex. & + & (Flynn et al., 2012) \\
\hline RPA3 & G & Member of RPA complex. & + & \\
\hline RPA-bound telomeres & $S$ & $\begin{array}{l}\text { A non-sequence specific ssDNA binding complex of RPA1, RPA2 and } \\
\text { RPA3. Replaces POT1 and recruits ATR to ssDNA at telomeres. }\end{array}$ & + & \\
\hline HNRNPA1 & G & $\begin{array}{l}\text { Displaces RPA from ssDNA, promoting the RPA-POT1 switch during } \\
\text { the cell cycle. }\end{array}$ & - & \\
\hline ATR & G & $\begin{array}{l}\text { Ser/Thr kinase, DNA damage sensing and checkpoint protein. } \\
\text { Phosphorylates CHEK1. Activates HR at telomeres upon recruitment } \\
\text { by RPA (Flynn et al., 2012). Inhibition reduces ALT (Flynn et al., }\end{array}$ & + & $\begin{array}{l}\text { (Flynn et al., 2012), } \\
\text { (Flynn et al., 2015), (Deeg } \\
\text { et al., 2016), (Dilley et al., } \\
\text { 2016) }\end{array}$ \\
\hline
\end{tabular}


2015). Inhibition does not universally kill ALT cells (Deeg et al.,

2016). Disruption of ATR and CHEK1 inhibits recruitment of HOP2 to

telomeres (Dilley et al., 2016).

\begin{tabular}{|c|c|c|c|c|}
\hline CHEK1 & G & $\begin{array}{l}\text { Disruption of ATR and CHEK1 inhibits recruitment of HOP2 to } \\
\text { telomeres (Dilley et al., 2016). }\end{array}$ & + & (Dilley et al., 2016) \\
\hline RAD51 & G & $\begin{array}{l}\text { Is recruited to RPA-bound telomeres. Promotes homology search and } \\
\text { strand-exchange (Cho et al., 2014). May supppress c-circle formation } \\
\text { (Jia-Min Zhang et al., 2019). }\end{array}$ & + & $\begin{array}{l}\text { (Cho et al., 2014), } \\
\text { (Jia-Min Zhang et al., } \\
\text { 2019) }\end{array}$ \\
\hline PSMC3IP (HOP2) & G & $\begin{array}{l}\text { In complex with MND1 and together with RAD51 facilitates long- } \\
\text { range DNA movement, homology search and strand exchange. }\end{array}$ & + & \multirow{3}{*}{ (Cho et al., 2014) } \\
\hline MND1 & $\mathrm{G}$ & $\begin{array}{l}\text { In complex with HOP2 and together with RAD51 facilitates long-range } \\
\text { DNA movement, homology search and strand exchange. }\end{array}$ & + & \\
\hline HOP2-MND1 & $\mathrm{C}$ & $\begin{array}{c}\text { Together with RAD51 facilitates long-range DNA movement, } \\
\text { homology search and strand exchange. }\end{array}$ & + & \\
\hline RAD52 & G & $\begin{array}{l}\text { Required for ALT in some cases, but not for C-circle formation. } \\
\text { Promotes strand invasion and telomeric D-loop formation even in the } \\
\text { presence of RPA (Jia-Min Zhang et al., 2019). May promote annealing } \\
\text { of resected single-stranded telomeres to potential templates (Min et al., }\end{array}$ & + & $\begin{array}{l}\text { (Jia-Min Zhang et al., } \\
\text { 2019), } \\
\text { (Min et al., 2019) }\end{array}$ \\
\hline
\end{tabular}
2019).

\begin{tabular}{|c|c|c|c|c|}
\hline \multicolumn{5}{|c|}{ Template directed synthesis } \\
\hline \multicolumn{5}{|c|}{ Polymerase directed synthesis of the telomeric $G$ - and $C$-strands } \\
\hline POLD3 & G & $\begin{array}{l}\text { Subunit of DNA polymerase delta. Required for synthesis of G- and C- } \\
\text { strands. }\end{array}$ & + & \multirow{5}{*}{ (Dilley et al., 2016) } \\
\hline PCNA & G & $\begin{array}{l}\text { Cofactor of DNA polymerase delta. Part of DNA-clamp complex. } \\
\text { Interacts with POLD3 to recruit polymerase delta to ALT telomeres. }\end{array}$ & + & \\
\hline RFC1 & G & $\begin{array}{l}\text { DNA-dependent ATPase. Part of RFC clamp loading complex, binds to } \\
\text { 3' primers and facilitates DNA synthesis at both strands. Senses } \\
\text { damaged telomeres and facilitates PCNA-POLD3 loading. }\end{array}$ & + & \\
\hline $\begin{array}{l}\text { clamp loading } \\
\text { complex }\end{array}$ & $\mathrm{C}$ & Pequired for PCNA-POLD3 telomere localization & + & \\
\hline PNCA clamp & $\mathrm{C}$ & Processive synthesis and strand displacement & + & \\
\hline \multicolumn{5}{|c|}{ Holiday Junction (HJ) processing } \\
\hline \multicolumn{5}{|c|}{ HJ dissolution with telomere synthesis } \\
\hline MRN & $\mathrm{C}$ & $\begin{array}{c}\text { Acts at first stages of DSBR: detects and tethers DSBs, activates } \\
\text { damage response. May inhibit NHEJ by promoting generation of } 3^{\prime} \\
\text { overhang after leading strand synthesis (Dimitrova and de Lange, } \\
\text { 2009). Depletion or sequestration of MRN complex supresses the ALT } \\
\text { pathway (Clynes et al., 2015). }\end{array}$ & + & $\begin{array}{l}\text { (Dimitrova and de Lange, } \\
\text { 2009), } \\
\text { (Clynes et al., 2015) }\end{array}$ \\
\hline MRE11 & G & Member of MRN complex. An endonuclease. & + & \multirow{3}{*}{$\begin{array}{l}\text { (Lafrance-Vanasse et al., } \\
\text { 2015) }\end{array}$} \\
\hline RAD50 & G & Member of MRN complex. An ATPase. & + & \\
\hline NBN (NBS1) & G & Member of MRN complex. An adapter protein. & + & \\
\hline SP100 & G & Sequesters MRN away from ABPs. Suppresses ALT. & - & (Jiang et al., 2005) \\
\hline BTR & $\mathrm{C}$ & $\begin{array}{l}\text { Promotes long-tract telomere extension followed by } 5^{\prime}-3^{\prime} \text { end resection } \\
\text { and telomeric dissolution. }\end{array}$ & + & $\begin{array}{l}\text { (Sobinoff et al., 2017), } \\
\text { (Min et al., 2019) }\end{array}$ \\
\hline BLM & G & Member of BTR complex. RecQ DNA helicase. & + & \multirow{4}{*}{ (Sobinoff et al., 2017) } \\
\hline TOP3A & G & Member of BTR complex. DNA topoisomerase. & + & \\
\hline RMI1 & G & Member of BTR complex. Accessory protein. & + & \\
\hline RMI2 & G & Member of BTR complex. Accessory protein. & + & \\
\hline \multicolumn{5}{|c|}{ HJ resolution preventing telomere synthesis } \\
\hline ERRC1/4 & $\mathrm{C}$ & $\begin{array}{l}\text { Promotes telomeric resolution, represses association of POLD3 with } \\
\text { telomeres and prevents telomere synthesis by resolving recombination } \\
\text { intermediates. }\end{array}$ & - & (Zhu et al., 2003) \\
\hline SLX1 & G & Holiday Junction resolvase. & - & \multirow{4}{*}{ (Sobinoff et al., 2017) } \\
\hline SLX4 & G & Scaffold for endonucleases' assembly. Recruits endonucleases. & - & \\
\hline SLX1A & G & Catalytic subunit of SLX4-SLX1 & - & \\
\hline SLX1B & G & Catalytic subunit of SLX4-SLX1 & - & \\
\hline ERCC1 & G & $\begin{array}{c}\text { Forms a heterodimer with ERCC4 and supresses recombination with } \\
\text { interstitial telomeric sequences. }\end{array}$ & - & \multirow{2}{*}{ (Zhu et al., 2003) } \\
\hline ERCC4 & G & $\begin{array}{l}\text { Forms a heterodimer with ERCC1 and supresses recombination with } \\
\text { interstitial telomeric sequences. }\end{array}$ & - & \\
\hline
\end{tabular}

This is a provisional file, not the final typeset article 
${ }^{a}$ Node types: $\mathrm{G}$ - gene, $\mathrm{C}$ - complex, I - isoform.

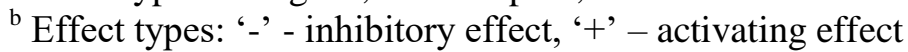

Table S4. Functional role of the TEL pathway nodes.

\begin{tabular}{|c|c|c|c|c|}
\hline Name (alias) & Type & Description & Effect & Reference \\
\hline \multicolumn{5}{|c|}{ Nuclear TERT (TERT activation and recruitment) } \\
\hline \multicolumn{5}{|c|}{$\begin{array}{c}\text { TERT expression, post-transcriptional modifications and factors involved in recruitment of the active hTERT } \\
\text { protein to the nucleus }\end{array}$} \\
\hline TERT & $\mathrm{G}$ & The catalytic subunit of telomerase & + & (Cohen et al., 2007) \\
\hline KPNA1 & G & $\begin{array}{l}\text { Importin alpha 5. Interacts with nuclear localization signal of hTERT and } \\
\text { promotes its nuclear import. }\end{array}$ & + & \multirow{2}{*}{ (Jeong et al., 2015) } \\
\hline RAN & G & $\begin{array}{c}\text { GTPase that affects disassembly of importin-cargo complexes and is important for } \\
\text { importin alpha } 5 \text { mediated nuclear import of hTERT. }\end{array}$ & + & \\
\hline IPO7 & G & $\begin{array}{l}\text { Importin alpha 7. Interacts with the C-terminal nuclear localization signal of } \\
\text { hTERT and promotes its alternative nuclear import. }\end{array}$ & + & \multirow{2}{*}{ (Frohnert et al., 2014) } \\
\hline RANBP2 & G & $\begin{array}{l}\text { A nuclear pore complex member. Plays an important role in importin alpha } 7 \\
\text { mediated nuclear import of hTERT. }\end{array}$ & + & \\
\hline HSP90 & I & $\begin{array}{l}\text { A chaperone that assures proper hTERT conformation to promote its nuclear } \\
\text { import. }\end{array}$ & + & \multirow{5}{*}{ (Jeong et al., 2015) } \\
\hline HSP90AA1 & G & HSP90 isoform & + & \\
\hline HSP90AA2 & G & HSP90 isoform & + & \\
\hline HSP90AB1 & G & HSP90 isoform & + & \\
\hline PTGES3 & G & $\begin{array}{l}\text { p23, a co-chaperone that binds HSP90 dimer and stabilizes the HSP90-hTERT } \\
\text { complex. }\end{array}$ & + & \\
\hline STUB1 & G & $\begin{array}{l}\text { CHIP, a ubiquitine ligase that marks cytoplasmic hTERT for degradation (Lee et } \\
\text { al., 2010). }\end{array}$ & - & (Lee et al., 2010) \\
\hline \multicolumn{5}{|c|}{ hTR maturation } \\
\hline \multicolumn{5}{|c|}{$\begin{array}{c}\text { TERC expression, and opposing processes of degradation of the transcripts or stabilitzation and maturation } \\
\text { into functional hTR template }\end{array}$} \\
\hline TERC & G & The RNA template (hTR) of telomerase & + & $\begin{array}{l}\text { (Cohen et al., 2007), } \\
\text { (Cayuela et al., 2005) }\end{array}$ \\
\hline PARN & G & $\begin{array}{c}\text { Ribonuclease that removes oligo(A) tails from nascent hTR, adds poly(A) tails and } \\
\text { promotes hTR maturation. }\end{array}$ & + & $\begin{array}{l}\text { (Moon et al., 2015), } \\
\text { (Boyraz et al., 2016) }\end{array}$ \\
\hline TRAMP & $\mathrm{C}$ & $\begin{array}{l}\text { A polyadenylation complex consisting of PAPD5 (TENT4B), MTR4 (MTREX) } \\
\text { and AIR2 (ZCCHC7). Adds oligo(A) tails to nascent hTRs and marks them for } \\
\text { degradation by the exosomes. }\end{array}$ & - & (Boyraz et al., 2016) \\
\hline $\begin{array}{l}\text { TENT4B } \\
\text { (PAPD5) }\end{array}$ & G & Catalytic subunit of the TRAMP complex. & - & $\begin{array}{l}\text { (Tseng et al., 2015), } \\
\text { (Moon et al., 2015) }\end{array}$ \\
\hline MTREX (MTR4) & G & A helicase, part of the TRAMP complex. & - & \multirow{2}{*}{ (Tseng et al., 2015) } \\
\hline ZCCHC7 (AIR2) & G & RNA-binding factor, member of the TRAMP complex. & - & \\
\hline $\begin{array}{l}\text { DKC1-NOP10- } \\
\text { NHP2-NAF1 }\end{array}$ & $\mathrm{C}$ & $\begin{array}{l}\text { This complex binds hTR contranslationally, protects it from degradation and leads } \\
\text { to maturation in Cajal bodies. }\end{array}$ & + & \multirow{6}{*}{$\begin{array}{l}\text { (Schmidt and Cech, } \\
\text { 2015) }\end{array}$} \\
\hline DKC1 & G & $\begin{array}{l}\text { Key component of telomerase; part of hTR maturation complex DKC1-NOP10- } \\
\text { NHP2-NAF1 }\end{array}$ & + & \\
\hline NOP10 & G & $\begin{array}{l}\text { Small nucleolar ribonucleoprotein. Member of DKC1-NOP10-NHP2-NAF1 } \\
\text { complex. }\end{array}$ & + & \\
\hline NHP2 & G & $\begin{array}{l}\text { Small nucleolar ribonucleoprotein. Member of DKC1-NOP10-NHP2-NAF1 } \\
\text { complex. }\end{array}$ & + & \\
\hline NAF1 & $\mathrm{G}$ & $\begin{array}{l}\text { Ribonucleoprotein assembly factor. Member of DKC1-NOP10-NHP2-NAF1 } \\
\text { complex. }\end{array}$ & + & \\
\hline GAR1 & G & $\begin{array}{l}\text { Ribonucleoprotein assembly factor: replaces NAF1 during ribonucleoprotein } \\
\text { complex maturation. Member of DKC1-NOP10-NHP2-GAR1 complex. }\end{array}$ & + & \\
\hline WRAP53 & G & $\begin{array}{l}\text { RNA chaperone that promotes proper localization of hTR to Cajal bodies. Also } \\
\text { may assist in hTR folding after telomerase assembly. }\end{array}$ & + & (Chen et al., 2018) \\
\hline \multicolumn{5}{|c|}{ Telomerase assembly } \\
\hline \multicolumn{5}{|c|}{ Main components of the telomerase complex and additional factors promoting its assembly } \\
\hline TERT & $\mathrm{G}$ & The catalytic subunit of telomerase & + & (Cohen et al., 2007) \\
\hline TERC & G & The RNA template (hTR) of telomerase & + & $\begin{array}{l}\text { (Cohen et al., 2007), } \\
\text { (Cayuela et al., 2005) }\end{array}$ \\
\hline DKC1 & G & Core component of telomerase: stabilizes the complex by binding to hTR. & + & (Schmidt and Cech, \\
\hline
\end{tabular}


2015)

\begin{tabular}{|c|c|c|c|c|}
\hline Pontin/Reptin & $\mathrm{C}$ & ATPases that are shown to act together and ensure proper telomerase assembly. & + & \multirow{3}{*}{$\begin{array}{c}\text { (Venteicher et al., } \\
\text { 2008) }\end{array}$} \\
\hline RUVBL1 & $\mathrm{G}$ & Pontin: part of pontin/reptin complex. Interacts directly with hTERT. & + & \\
\hline RUVBL2 & G & Reptin: part of pontin/reptin complex. & + & \\
\hline \multicolumn{5}{|c|}{ Recruitment to telomeres and synthesis } \\
\hline \multicolumn{5}{|c|}{ Factors recruiting the telomerase assembly to the telomeres and promoting telomere synthesis } \\
\hline CST & $\mathrm{C}$ & $\begin{array}{l}\text { Has dual role in the pathway. Recruits telomerase to telomeres, but limits its } \\
\text { presence to one extension cycle only, competing with POT1-TPP1 for telomere } \\
\text { binding. Recruits polymerase alpha to complete telomere synthesis. }\end{array}$ & + & \multirow{5}{*}{ (Chen et al., 2012) } \\
\hline CTC1 & G & Member of CST complex. & + & \\
\hline STN1 & G & Member of CST complex. Stimulates the activity of DNA polymerase alpha. & + & \\
\hline TEN1 & G & Member of CST complex. & + & \\
\hline Telomerase & $\mathrm{C}$ & Enzyme that counteracts telomeric DNA shortening & + & \\
\hline
\end{tabular}

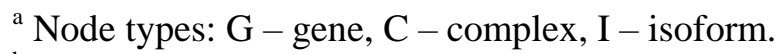

${ }^{\text {b }}$ Effect types: '-' - inhibitory effect, '+' - activating effect

\section{Pathway Signal Flow algorithm}

For pathway activity estimation from gene expression data we have used the Pathway Signal Flow (PSF) algorithm, implemented in the PSFC app for Cytoscape, v1.1.8 (Nersisyan et al., 2015b). In this particular study, we have made use of a higher level Cytoscape app, TMM v0.8 that uses PSFC as a dependency. It compares TMM pathway activation patterns with experimental annotations, uses PSFC for pathway activity computation and it also produces reports for TMM phenotype comparison across samples. The app (optionally) computes the fold change (FC) of each gene by taking the ratio of its expression to the average expression across the samples of the respective data set.

The PSF algorithm (Arakelyan et al., 2013; Nersisyan et al., 2015b, 2016) computes the strength of the signal propagated from the pathway inputs to the outputs through pairwise interactions between nodes, based on their fold change (FC) expression values. In this study, missing values were assigned an FC value of 1. For each source-target interaction, the $\mathrm{FC}$ values were multiplied for edges of type activation $\left(\mathrm{FC}_{\text {source }} * \mathrm{FC}_{\text {target }}\right)$ and inversely multiplied for edges of type inhibition $\left(1 / \mathrm{FC}_{\text {source }} * \mathrm{FC}_{\text {target }}\right)$. The signal propagation starts from input nodes, spreads through the intermediate nodes and arrives at the sink nodes (labeled "ALT" and "TEL", respectively). The PSF scores at the sink nodes reflect the overall activity of the pathways (Figure S1).

The product of multiple signals from many sources was assigned as the signal at the target node (the "multiplication" option in PSFC). PSFC also allows for assigning explicit functions to deal with multiple incoming edges onto specific nodes. We have assigned the function "min" to nodes combining complex subunits (as the gene with minimum expression defines the activity of the complex), and the function "max" to homologous genes, where it is unknown which transcript plays the described role (and assumed that the most expressed one should), and finally we assigned the function "sum" to the linker between two hTERT nuclear import pathways, as each of them independently contribute to the protein's entry to the nucleus. 


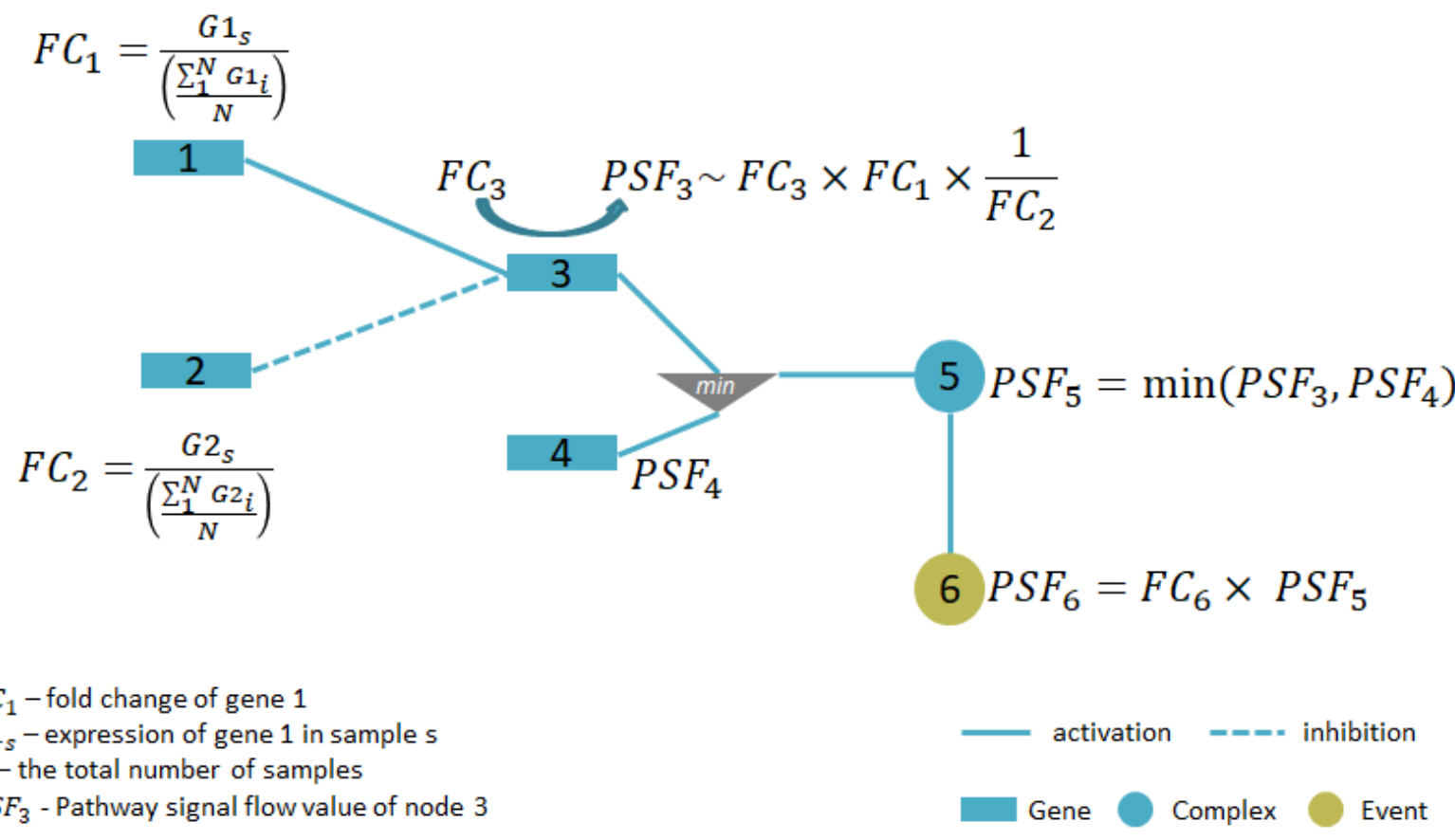

Figure S1. Signal propagation with the pathway signal flow algorithm.

The fold change (FC) values for each gene are computed as its expression in the given sample relative to its mean expression across the samples. After initial assignment of FC values, the pathway signal flow (PSF) values are computed by multiplying the source and target values (PSF if already computed or FC if the node doesn't have upstream interactors) on the edges of type activation, or performing inverse multiplication on the edges of type inhibition. The operator nodes ( $\mathrm{min}$ ) modulate the PSF values by setting a certain rule on multiple input signals (in this case: the minimum value of the two upstream PSF values on the node of type Complex). 
Cell lines

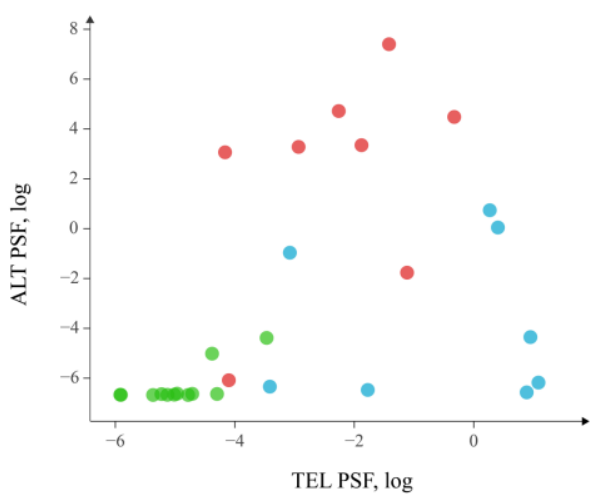

T1_1 (A2780) T1_2 (A2780)

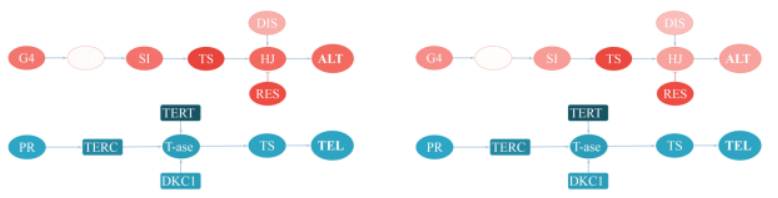

T2_1 (C33A)

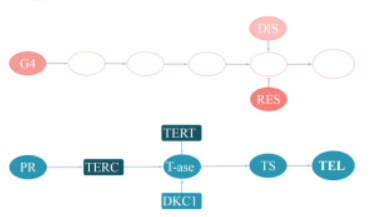

T3_1 (HT1080)
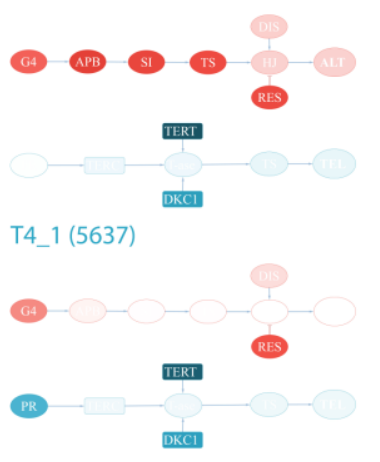

T2_2 (C33A)

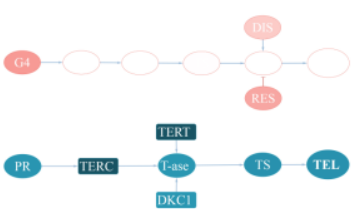

T3_2 (HT1080)

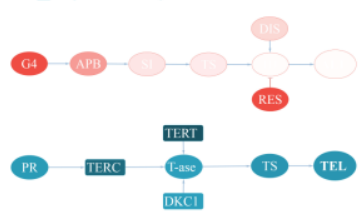

T4_2 (5637)

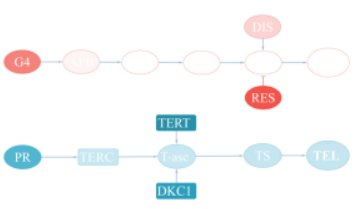

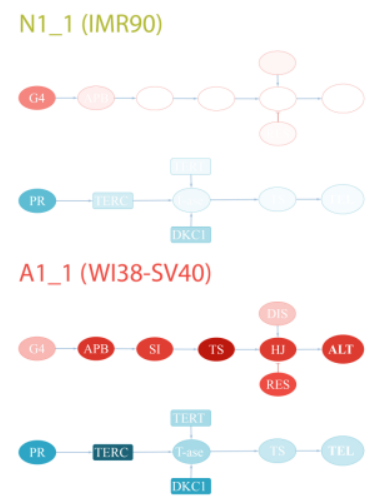

A2 1 (SKLU)

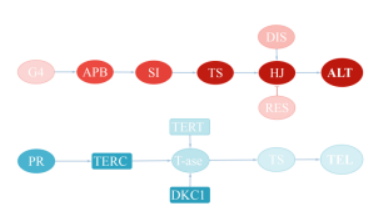

A3_1 (KMST6)

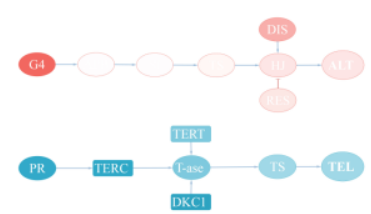

A4_1 (SUSM1)

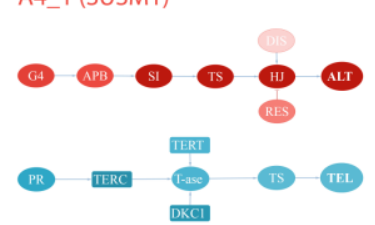

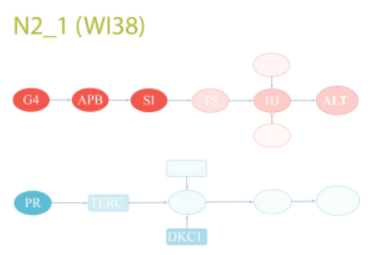

A1_2 (WI38-SV40)
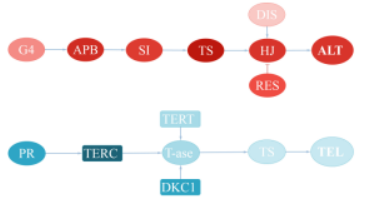

A2_2 (SKLU)

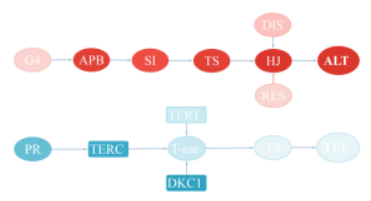

A3_2 (KMST6)

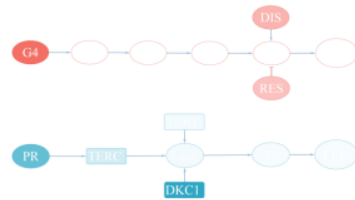

A4_2 (SUSM1)

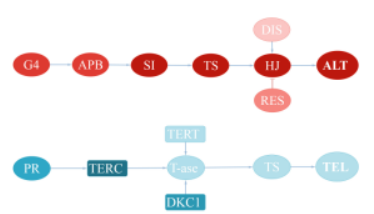

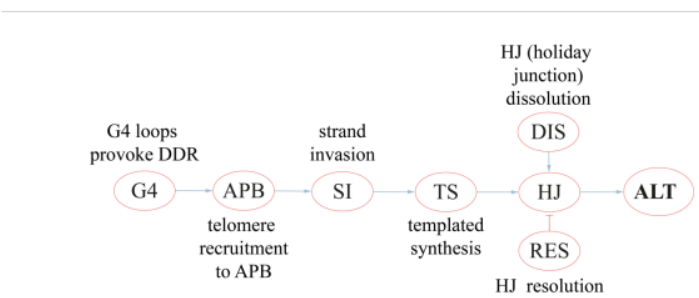

$\mathrm{HJ}$ resolution

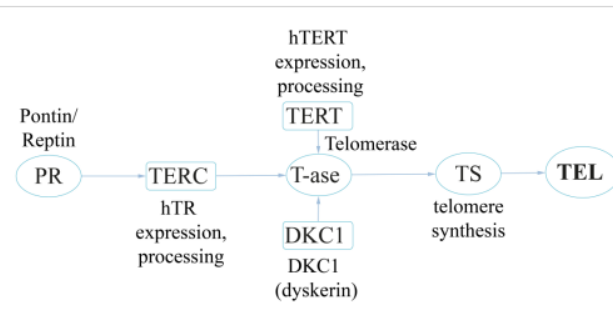

Figure S2. Cell line specific pathway activation patterns at the level of individual pathway branches. Top left: 2D plots with samples placed according to the TEL (x axis) and the ALT (y axis) pathway activity PSF values. The samples are colored according to the experimental TMM annotations. Technical replicates are distinguished with_1 and_2 suffices. Horizontal and vertical dash lines separate ALT ${ }^{+}$from ALT ${ }^{-}$and TEL ${ }^{+}$ from TEL ${ }^{-}$experimentally annotated samples based on support vector machine classification on the ALT and the TEL PSF values. Other panels: Pathway activation patterns at the level of branches in each sample.

Bottom: node abbreviations in the pathways.

This is a provisional file, not the final typeset article 
Liposarcoma tissues
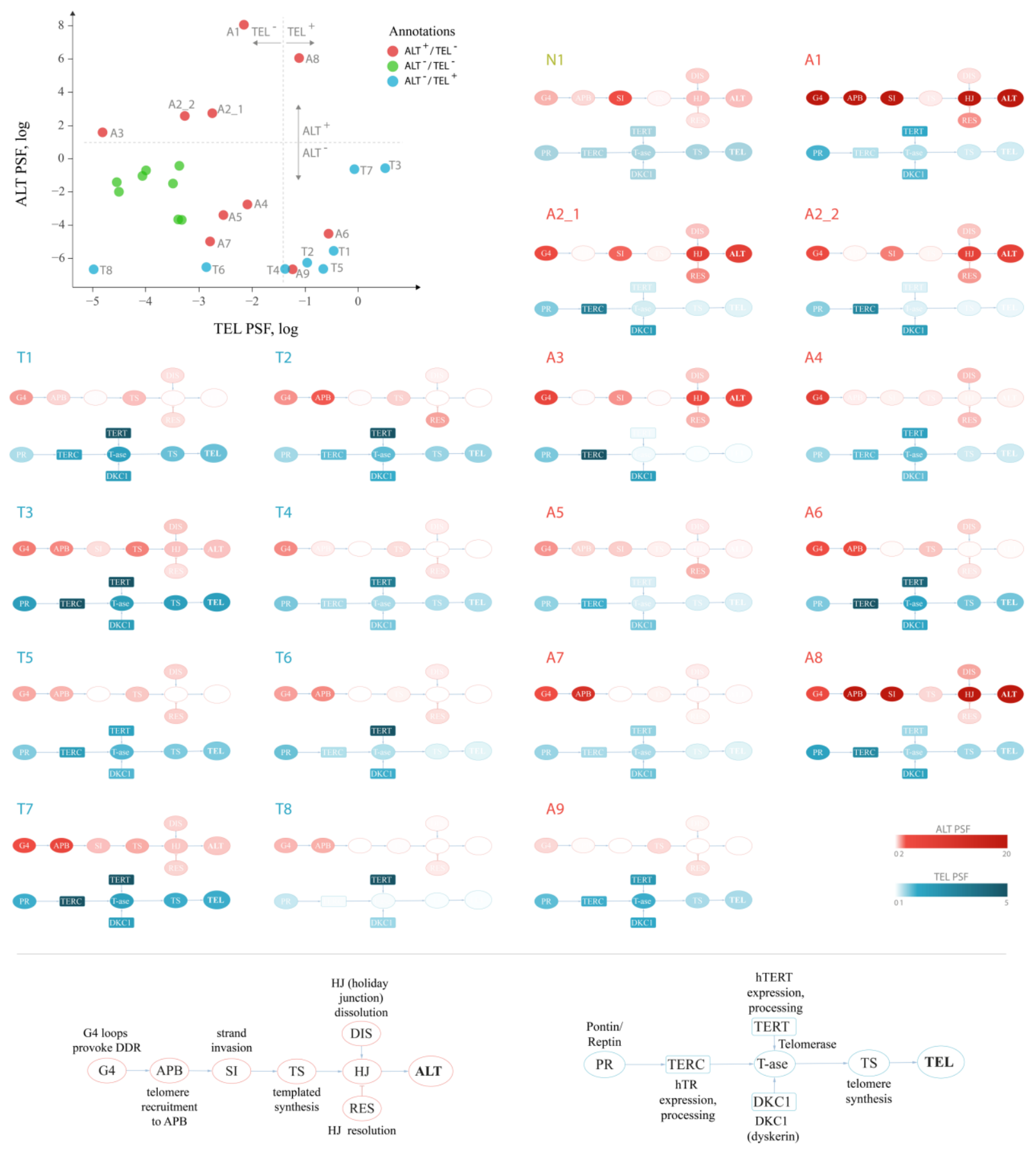

Figure S3. Tissue specific pathway activation patterns at the level of individual pathway branches.

Top left: 2D plots with samples placed according to the TEL (x axis) and the ALT (y axis) pathway activity PSF values. The samples are colored according to the experimental TMM annotations. Technical replicates are distinguished with _1 and_2 suffices. Horizontal and vertical dash lines separate $\mathrm{ALT}^{+}$from $\mathrm{ALT}^{-}$and TEL ${ }^{+}$ from TEL ${ }^{-}$experimentally annotated samples based on support vector machine classification on the ALT and the TEL PSF values. Other panels: Pathway activation patterns at the level of branches in each sample.

Bottom: node abbreviations in the pathways. 


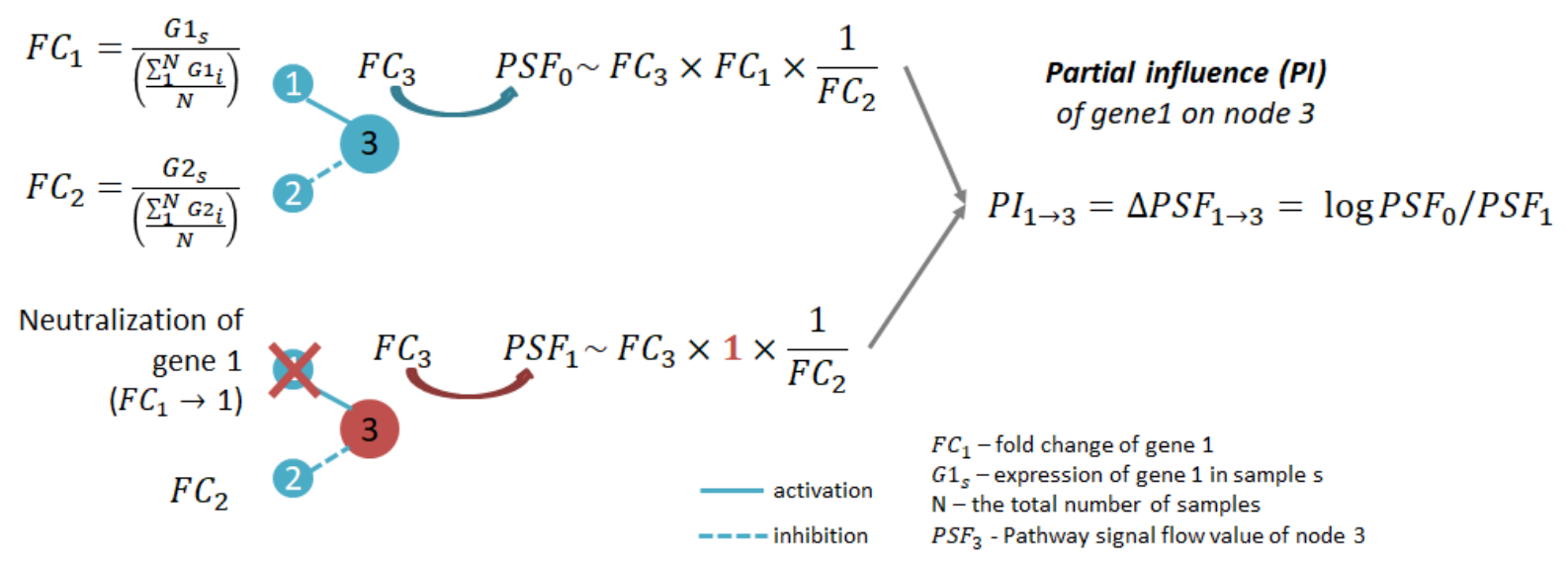

Figure S4. A toy example of computation of the partial influence (PI) of a given source node on the PSF activity of the target node.

Top: computation of the PSF activity of the node $3\left(\mathrm{PSF}_{0}\right)$, given the fold change $(\mathrm{FC})$ values of the node 1 and 2. Bottom: PSF activity of the node $3\left(\mathrm{PSF}_{1}\right)$ after setting the fold change of the node 1 to $\mathrm{FC}=1$, thus neutralizing its influence. The difference between the PSF activity of the node 3 before and after neutralizing the influence of the node 1 is the partial influence (PI) of the node 1 on node 3 activity.
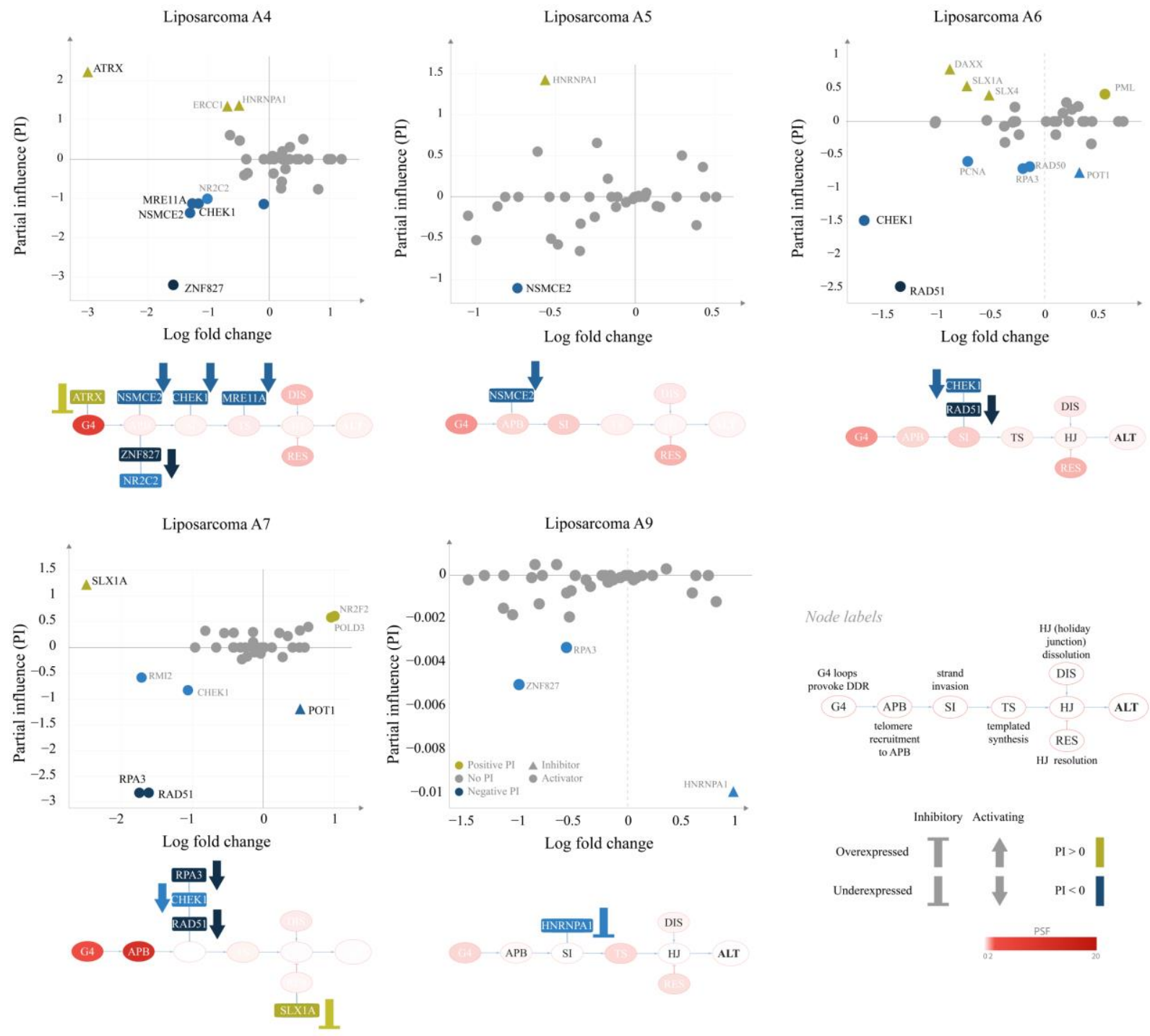

This is a provisional file, not the final typeset article 
Figure S5. Partial influence of nodes on the ALT pathway activity of the A5 and A9 liposarcoma tissues. Partial influence (PI) of each node is computed as the difference of the TEL node PSF value when the node is set to a fold change (FC) value of 1 . The most influential nodes are shown in the context of the pathway branches.
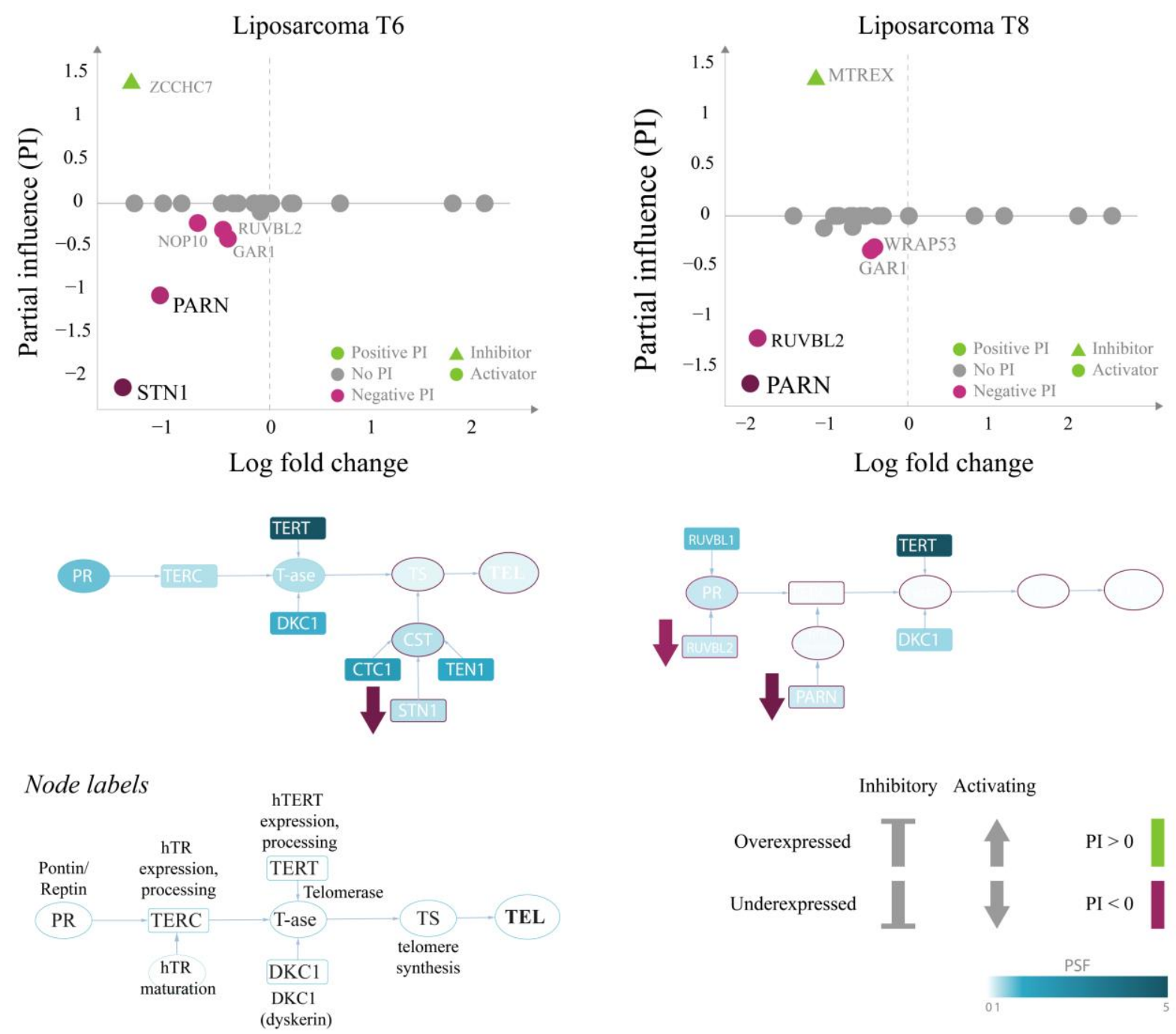

Figure S6. Partial influence of nodes on the TEL pathway activity of the T6 and T8 liposarcoma tissues. Partial influence (PI) of each node is computed as the difference of the TEL node PSF value when the node is set to a fold change (FC) value of 1 . The most influential nodes are shown in the context of the pathway branches. 
Table S5. Genes from the TelNet database that are marked as either having a role in ALT or Telomerase-mediated telomere maintenance pathways.

\begin{tabular}{|c|c|c|c|c|c|}
\hline Entrez & Symbol & TMM & Entrez & Symbol & TMM \\
\hline 52 & ACP1 & ALT & 546 & ATRX & Telomerase-mediated \\
\hline 367 & $\mathrm{AR}$ & $A L T$ & 553 & AVPR1B & Telomerase-mediated \\
\hline 641 & BLM & $A L T$ & 624 & BDKRB2 & Telomerase-mediated \\
\hline 655 & BMP7 & ALT & 815 & CAMK2A & Telomerase-mediated \\
\hline 675 & BRCA2 & ALT & 908 & ССТ6А & Telomerase-mediated \\
\hline 818 & CAMK2G & ALT & 924 & CD7 & Telomerase-mediated \\
\hline 860 & RUNX2 & ALT & 1030 & CDKN2B & Telomerase-mediated \\
\hline 1026 & CDKN1A & ALT & 1111 & CHEK1 & Telomerase-mediated \\
\hline 1050 & CEBPA & ALT & 1198 & CLK3 & Telomerase-mediated \\
\hline 1051 & CEBPB & ALT & 1432 & MAPK14 & Telomerase-mediated \\
\hline 1763 & DNA2 & ALT & 1457 & CSNK2A1 & Telomerase-mediated \\
\hline 1786 & DNMT1 & ALT & 1499 & CTNNB1 & Telomerase-mediated \\
\hline 1869 & E2F1 & $\mathrm{ALT}$ & 1616 & DAXX & Telomerase-mediated \\
\hline 2072 & ERCC4 & $A L T$ & 1633 & DCK & Telomerase-mediated \\
\hline 2073 & ERCC5 & $A L T$ & 1736 & DKC1 & Telomerase-mediated \\
\hline 2175 & FANCA & $A L T$ & 1740 & DLG2 & Telomerase-mediated \\
\hline 2237 & FEN1 & $A L T$ & 1742 & DLG4 & Telomerase-mediated \\
\hline 2547 & XRCC6 & ALT & 1760 & DMPK & Telomerase-mediated \\
\hline 3020 & H3F3A & ALT & 1841 & DTYMK & Telomerase-mediated \\
\hline 3104 & ZBTB48 & $A L T$ & 1870 & $\mathrm{E} 2 \mathrm{~F} 2$ & Telomerase-mediated \\
\hline 3178 & HNRNPA1 & ALT & 1871 & $\mathrm{E} 2 \mathrm{F3}$ & Telomerase-mediated \\
\hline 3183 & HNRNPC & $A L T$ & 1874 & $\mathrm{E} 2 \mathrm{~F} 4$ & Telomerase-mediated \\
\hline 3190 & HNRNPK & ALT & 1875 & E2F5 & Telomerase-mediated \\
\hline 3192 & HNRNPU & $\mathrm{ALT}$ & 1876 & E2F6 & Telomerase-mediated \\
\hline 3659 & IRF1 & $\mathrm{ALT}$ & 1907 & EDN2 & Telomerase-mediated \\
\hline 3725 & JUN & $A L T$ & 2043 & EPHA4 & Telomerase-mediated \\
\hline 3978 & LIG1 & $A L T$ & 2099 & ESR1 & Telomerase-mediated \\
\hline 4084 & MXD1 & ALT & 2100 & ESR2 & Telomerase-mediated \\
\hline 4088 & SMAD3 & ALT & 2113 & ETS1 & Telomerase-mediated \\
\hline 4150 & MAZ & ALT & 2114 & ETS2 & Telomerase-mediated \\
\hline 4217 & MAP3K5 & ALT & 2115 & ETV1 & Telomerase-mediated \\
\hline 4221 & MEN1 & ALT & 2118 & ETV4 & Telomerase-mediated \\
\hline 4361 & MRE11 & ALT & 2130 & EWSR1 & Telomerase-mediated \\
\hline 4683 & NBN & ALT & 2242 & FES & Telomerase-mediated \\
\hline 5105 & PCK1 & ALT & 2261 & FGFR3 & Telomerase-mediated \\
\hline 5156 & PDGFRA & ALT & 2264 & FGFR4 & Telomerase-mediated \\
\hline 5307 & PITX1 & $\mathrm{ALT}$ & 2313 & FLI1 & Telomerase-mediated \\
\hline 5371 & PML & ALT & 2596 & GAP43 & Telomerase-mediated \\
\hline 5422 & POLA1 & $A L T$ & 2735 & GLI1 & Telomerase-mediated \\
\hline 5424 & POLD1 & $A L T$ & 2736 & GLI2 & Telomerase-mediated \\
\hline 5425 & POLD2 & $A L T$ & 3091 & HIF1A & Telomerase-mediated \\
\hline 5426 & POLE & ALT & 3181 & HNRNPA2B1 & Telomerase-mediated \\
\hline 5427 & POLE2 & ALT & 3184 & HNRNPD & Telomerase-mediated \\
\hline
\end{tabular}

This is a provisional file, not the final typeset article 


\begin{tabular}{|c|c|c|c|c|c|}
\hline 5429 & POLH & ALT & 3204 & HOXA7 & Telomerase-mediated \\
\hline 5468 & PPARG & ALT & 3320 & HSP90AA1 & Telomerase-mediated \\
\hline 5557 & PRIM1 & ALT & 3326 & HSP90AB1 & Telomerase-mediated \\
\hline 5558 & PRIM2 & ALT & 3417 & IDH1 & Telomerase-mediated \\
\hline 5599 & MAPK8 & ALT & 3654 & IRAK1 & Telomerase-mediated \\
\hline 5888 & RAD51 & ALT & 3717 & JAK2 & Telomerase-mediated \\
\hline 5889 & RAD51C & ALT & 3727 & JUND & Telomerase-mediated \\
\hline 5906 & RAP1A & ALT & 3937 & LCP2 & Telomerase-mediated \\
\hline 5925 & RB1 & ALT & 4149 & MAX & Telomerase-mediated \\
\hline 5981 & RFC1 & ALT & 4214 & MAP3K1 & Telomerase-mediated \\
\hline 5982 & RFC2 & ALT & 4215 & MAР3К3 & Telomerase-mediated \\
\hline 5983 & RFC3 & ALT & 4216 & MAP3K4 & Telomerase-mediated \\
\hline 5984 & RFC4 & ALT & 4233 & MET & Telomerase-mediated \\
\hline 5985 & RFC5 & ALT & 4286 & MITF & Telomerase-mediated \\
\hline 6093 & ROCK1 & ALT & 4436 & $\mathrm{MSH} 2$ & Telomerase-mediated \\
\hline 6119 & RPA3 & ALT & 4598 & MVK & Telomerase-mediated \\
\hline 6199 & RPS6KB2 & ALT & 4602 & MYB & Telomerase-mediated \\
\hline 6259 & RYK & ALT & 4609 & MYC & Telomerase-mediated \\
\hline 6612 & SUMO3 & ALT & 4613 & MYCN & Telomerase-mediated \\
\hline 6613 & SUMO2 & ALT & 4751 & NEK2 & Telomerase-mediated \\
\hline 6615 & SNAI1 & ALT & 4773 & NFATC2 & Telomerase-mediated \\
\hline 6670 & SP3 & ALT & 4790 & NFKB1 & Telomerase-mediated \\
\hline 6672 & SP100 & ALT & 4846 & NOS3 & Telomerase-mediated \\
\hline 6714 & SRC & ALT & 4914 & NTRK1 & Telomerase-mediated \\
\hline 6886 & TAL1 & ALT & 4931 & NVL & Telomerase-mediated \\
\hline 6932 & TCF7 & ALT & 5079 & PAX5 & Telomerase-mediated \\
\hline 7011 & TEP1 & ALT & 5287 & PIK3C2B & Telomerase-mediated \\
\hline 7025 & NR2F1 & ALT & 5395 & PMS2 & Telomerase-mediated \\
\hline 7026 & NR2F2 & ALT & 5570 & PKIB & Telomerase-mediated \\
\hline 7153 & TOP2A & ALT & 5576 & PRKAR2A & Telomerase-mediated \\
\hline 7156 & TOP3А & ALT & 5577 & PRKAR2B & Telomerase-mediated \\
\hline 7157 & TP53 & ALT & 5588 & PRKCQ & Telomerase-mediated \\
\hline 7158 & TP53BP1 & ALT & 5589 & PRKCSH & Telomerase-mediated \\
\hline 7161 & TP73 & ALT & 5594 & MAPK1 & Telomerase-mediated \\
\hline 7181 & NR2C1 & ALT & 5595 & MAPK3 & Telomerase-mediated \\
\hline 7182 & NR2C2 & ALT & 5609 & MAP2K7 & Telomerase-mediated \\
\hline 7323 & UBE2D3 & ALT & 5611 & DNAJC3 & Telomerase-mediated \\
\hline 7329 & UBE2I & ALT & 5793 & PTPRG & Telomerase-mediated \\
\hline 7341 & SUMO1 & ALT & 5879 & RAC1 & Telomerase-mediated \\
\hline 7345 & UCHL1 & ALT & 5970 & RELA & Telomerase-mediated \\
\hline 7421 & VDR & ALT & 6023 & RMRP & Telomerase-mediated \\
\hline 7486 & WRN & ALT & 6117 & RPA1 & Telomerase-mediated \\
\hline 7490 & WT1 & ALT & 6635 & SNRPE & Telomerase-mediated \\
\hline 7517 & XRCC3 & ALT & 6774 & STAT3 & Telomerase-mediated \\
\hline 7520 & XRCC5 & ALT & 6776 & STAT5A & Telomerase-mediated \\
\hline 7593 & MZF1 & ALT & 6787 & NEK4 & Telomerase-mediated \\
\hline 7913 & DEK & ALT & 6790 & AURKA & Telomerase-mediated \\
\hline
\end{tabular}




\begin{tabular}{|c|c|c|c|c|c|}
\hline 8289 & ARID1A & ALT & 6829 & SUPT5H & Telomerase-mediated \\
\hline 8379 & MAD1L1 & ALT & 6934 & TCF7L2 & Telomerase-mediated \\
\hline 8491 & MAP4K3 & ALT & 7012 & TERC & Telomerase-mediated \\
\hline 8553 & BHLHE40 & ALT & 7015 & TERT & Telomerase-mediated \\
\hline 8932 & MBD2 & ALT & 7020 & TFAP2A & Telomerase-mediated \\
\hline 9839 & ZEB2 & ALT & 7021 & TFAP2B & Telomerase-mediated \\
\hline 10038 & PARP2 & ALT & 7023 & TFAP4 & Telomerase-mediated \\
\hline 10111 & RAD50 & ALT & 7203 & СCT3 & Telomerase-mediated \\
\hline 10320 & IKZF1 & ALT & 7360 & UGP2 & Telomerase-mediated \\
\hline 10365 & KLF2 & ALT & 7515 & XRCC1 & Telomerase-mediated \\
\hline 10411 & RAPGEF3 & ALT & 7525 & YES1 & Telomerase-mediated \\
\hline 10445 & MCRS1 & ALT & 7707 & ZNF148 & Telomerase-mediated \\
\hline 10574 & CCT7 & ALT & 7849 & PAX8 & Telomerase-mediated \\
\hline 10575 & CCT4 & ALT & 8091 & HMGA2 & Telomerase-mediated \\
\hline 10576 & СCT2 & ALT & 8518 & IKBKAP & Telomerase-mediated \\
\hline 10635 & RAD51AP1 & ALT & 8550 & MAPKAPK5 & Telomerase-mediated \\
\hline 10664 & CTCF & ALT & 8573 & CASK & Telomerase-mediated \\
\hline 10714 & POLD3 & ALT & 8576 & STK16 & Telomerase-mediated \\
\hline 10715 & CERS1 & ALT & 8607 & RUVBL1 & Telomerase-mediated \\
\hline 11176 & BAZ2A & ALT & 8651 & SOCS1 & Telomerase-mediated \\
\hline 11335 & CBX3 & ALT & 8658 & TNKS & Telomerase-mediated \\
\hline 22928 & SEPHS2 & ALT & 8859 & STK19 & Telomerase-mediated \\
\hline 22948 & СCT5 & ALT & 8986 & RPS6KA4 & Telomerase-mediated \\
\hline 23028 & KDM1A & ALT & 8999 & CDKL2 & Telomerase-mediated \\
\hline 23137 & SMC5 & ALT & 9019 & MPZL1 & Telomerase-mediated \\
\hline 23293 & SMG6 & ALT & 9024 & BRSK2 & Telomerase-mediated \\
\hline 23515 & MORC3 & ALT & 9212 & AURKB & Telomerase-mediated \\
\hline 23649 & POLA2 & ALT & 9252 & RPS6KA5 & Telomerase-mediated \\
\hline 51564 & HDAC7 & ALT & 9314 & KLF4 & Telomerase-mediated \\
\hline 51750 & RTEL1 & ALT & 9475 & ROCK2 & Telomerase-mediated \\
\hline 54107 & POLE3 & ALT & 9878 & TOX4 & Telomerase-mediated \\
\hline 54984 & PINX1 & ALT & 10020 & GNE & Telomerase-mediated \\
\hline 55183 & RIF1 & ALT & 10270 & AKAP8 & Telomerase-mediated \\
\hline 55226 & NAT10 & ALT & 10694 & ССТ8 & Telomerase-mediated \\
\hline 55300 & $\mathrm{PI} 4 \mathrm{~K} 2 \mathrm{~B}$ & ALT & 10725 & NFAT5 & Telomerase-mediated \\
\hline 56655 & POLE4 & ALT & 10728 & PTGES3 & Telomerase-mediated \\
\hline 56848 & SPHK2 & ALT & 10738 & RFPL3 & Telomerase-mediated \\
\hline 56849 & TCEAL7 & ALT & 10746 & MAP3К2 & Telomerase-mediated \\
\hline 57804 & POLD4 & ALT & 10783 & NEK6 & Telomerase-mediated \\
\hline 60496 & AASDHPPT & ALT & 10842 & PPP1R17 & Telomerase-mediated \\
\hline 60561 & RINT1 & ALT & 10856 & RUVBL2 & Telomerase-mediated \\
\hline 64781 & CERK & ALT & 10892 & MALT1 & Telomerase-mediated \\
\hline 65220 & NADK & ALT & 10898 & CPSF4 & Telomerase-mediated \\
\hline 79648 & MCPH1 & ALT & 10971 & YWHAQ & Telomerase-mediated \\
\hline 79677 & SMC6 & ALT & 11200 & CHEK2 & Telomerase-mediated \\
\hline 80119 & PIF1 & ALT & 11221 & DUSP10 & Telomerase-mediated \\
\hline 80169 & CTC1 & ALT & 11284 & PNKP & Telomerase-mediated \\
\hline
\end{tabular}

This is a provisional file, not the final typeset article 


\begin{tabular}{|c|c|c|c|c|c|}
\hline 80198 & MUS81 & ALT & 22983 & MAST1 & Telomerase-mediated \\
\hline 80724 & ACAD10 & ALT & 23043 & TNIK & Telomerase-mediated \\
\hline 84126 & ATRIP & ALT & 23326 & USP22 & Telomerase-mediated \\
\hline 84464 & SLX4 & ALT & 23552 & CDK20 & Telomerase-mediated \\
\hline 84787 & KMT5C & ALT & 25842 & ASF1A & Telomerase-mediated \\
\hline 152485 & ZNF827 & ALT & 25849 & PARM1 & Telomerase-mediated \\
\hline 201516 & ZSCAN4 & ALT & 25865 & PRKD2 & Telomerase-mediated \\
\hline 286053 & NSMCE2 & ALT & 25913 & РОT1 & Telomerase-mediated \\
\hline 348825 & TPRXL & ALT & 26054 & SENP6 & Telomerase-mediated \\
\hline 493861 & EID3 & ALT & 26060 & APPL1 & Telomerase-mediated \\
\hline 548593 & SLX1A & ALT & 26585 & GREM1 & Telomerase-mediated \\
\hline 100134934 & TEN1 & ALT & 29094 & LGALSL & Telomerase-mediated \\
\hline 100421108 & LOC100421108 & ALT & 50485 & SMARCAL1 & Telomerase-mediated \\
\hline \multirow[t]{34}{*}{100507436} & MICA & ALT & 51378 & ANGPT4 & Telomerase-mediated \\
\hline & & & 51765 & STK26 & Telomerase-mediated \\
\hline & & & 53340 & SPA17 & Telomerase-mediated \\
\hline & & & 54433 & GAR1 & Telomerase-mediated \\
\hline & & & 55120 & FANCL & Telomerase-mediated \\
\hline & & & 55135 & WRAP53 & Telomerase-mediated \\
\hline & & & 55164 & SHQ1 & Telomerase-mediated \\
\hline & & & 55197 & RPRD1A & Telomerase-mediated \\
\hline & & & 55505 & NOP10 & Telomerase-mediated \\
\hline & & & 55589 & BMP2K & Telomerase-mediated \\
\hline & & & 55651 & NHP2 & Telomerase-mediated \\
\hline & & & 55723 & ASF1B & Telomerase-mediated \\
\hline & & & 55869 & HDAC8 & Telomerase-mediated \\
\hline & & & 57144 & PAK5 & Telomerase-mediated \\
\hline & & & 57410 & SCYL1 & Telomerase-mediated \\
\hline & & & 64799 & $\mathrm{IQCH}$ & Telomerase-mediated \\
\hline & & & 79366 & HMGN5 & Telomerase-mediated \\
\hline & & & 79934 & $\mathrm{COQ} 8 \mathrm{~B}$ & Telomerase-mediated \\
\hline & & & 79977 & GRHL2 & Telomerase-mediated \\
\hline & & & 80351 & TNKS2 & Telomerase-mediated \\
\hline & & & 84152 & PPP1R1B & Telomerase-mediated \\
\hline & & & 92335 & STRADA & Telomerase-mediated \\
\hline & & & 92345 & NAF1 & Telomerase-mediated \\
\hline & & & 117283 & IP6K3 & Telomerase-mediated \\
\hline & & & 140609 & NEK7 & Telomerase-mediated \\
\hline & & & 140690 & CTCFL & Telomerase-mediated \\
\hline & & & 170506 & DHX36 & Telomerase-mediated \\
\hline & & & 225689 & MAPK15 & Telomerase-mediated \\
\hline & & & 256281 & NUDT14 & Telomerase-mediated \\
\hline & & & 283455 & KSR2 & Telomerase-mediated \\
\hline & & & 284086 & NEK8 & Telomerase-mediated \\
\hline & & & 285220 & EPHA6 & Telomerase-mediated \\
\hline & & & 340061 & TMEM173 & Telomerase-mediated \\
\hline & & & 440275 & EIF2AK4 & Telomerase-mediated \\
\hline
\end{tabular}




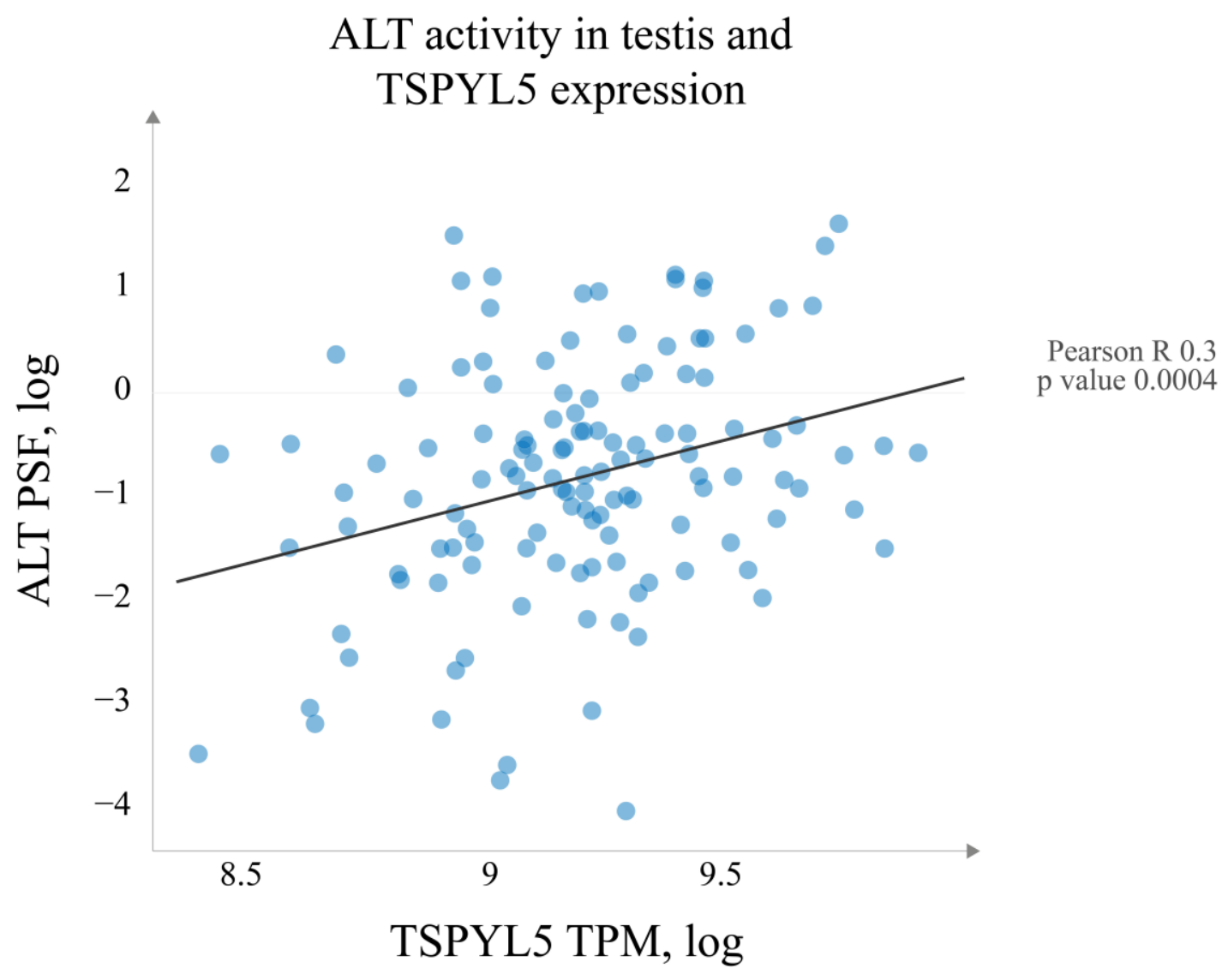

Figure S7. ALT pathway activity and expression of TSPYL5. ALT pathway PSF values show slight correlation (Pearson correlation R 0.03) with the expression of the testis-specific Y-encoded-like protein 5 (TSPYL5).

\section{References}

Aragón, L. (2018). The Smc5/6 Complex: New and Old Functions of the Enigmatic Long-Distance Relative. Annu. Rev. Genet. 52, 89107. doi:10.1146/annurev-genet-120417-031353.

Boyraz, B., Moon, D. H., Segal, M., Muosieyiri, M. Z., Aykanat, A., Tai, A. K., et al. (2016). Posttranscriptional manipulation of TERC reverses molecular hallmarks of telomere disease. J. Clin. Invest. 126, 3377-82. doi:10.1172/JCI87547.

Cayuela, M. L., Flores, J. M., and Blasco, M. A. (2005). The telomerase RNA component Terc is required for the tumour-promoting effects of Tert overexpression. EMBO Rep. 6, 268-274. doi:10.1038/sj.embor.7400359.

Chen, L.-Y., Redon, S., and Lingner, J. (2012). The human CST complex is a terminator of telomerase activity. Nature 488, 540-4. doi:10.1038/nature11269.

Chen, L., Roake, C. M., Freund, A., Batista, P. J., Tian, S., Yin, Y. A., et al. (2018). An Activity Switch in Human Telomerase Based on RNA Conformation and Shaped by TCAB1. Cell 174, 218-230.e13. doi:10.1016/j.cell.2018.04.039.

Cho, N. W., Dilley, R. L., Lampson, M. A., and Greenberg, R. A. (2014). Interchromosomal homology searches drive directional ALT telomere movement and synapsis. Cell 159, 108-121. doi:10.1016/j.cell.2014.08.030.

Chung, I., Osterwald, S., Deeg, K. I., and Rippe, K. (2012). PML body meets telomere: the beginning of an ALTernate ending? Nucleus 3, 263-75. doi:10.4161/nucl.20326.

This is a provisional file, not the final typeset article 
Clynes, D., Jelinska, C., Xella, B., Ayyub, H., Scott, C., Mitson, M., et al. (2015). Suppression of the alternative lengthening of telomere pathway by the chromatin remodelling factor ATRX. Nat. Commun. 6, 7538. doi:10.1038/ncomms8538.

Cohen, S. B., Graham, M. E., Lovrecz, G. O., Bache, N., Robinson, P. J., and Reddel, R. R. (2007). Protein composition of catalytically active human telomerase from immortal cells. Science 315, 1850-3. doi:10.1126/science.1138596.

Conomos, D., Reddel, R. R., and Pickett, H. A. (2014). NuRD-ZNF827 recruitment to telomeres creates a molecular scaffold for homologous recombination. doi:10.1038/nsmb.2877.

Deeg, K. I., Chung, I., Bauer, C., and Rippe, K. (2016). Cancer Cells with Alternative Lengthening of Telomeres Do Not Display a General Hypersensitivity to ATR Inhibition. Front. Oncol. 6, 186. doi:10.3389/fonc.2016.00186.

Dilley, R. L., Verma, P., Cho, N. W., Winters, H. D., Wondisford, A. R., and Greenberg, R. A. (2016). Break-induced telomere synthesis underlies alternative telomere maintenance. Nature 539, 54-58. doi:10.1038/nature20099.

Dimitrova, N., and de Lange, T. (2009). Cell Cycle-Dependent Role of MRN at Dysfunctional Telomeres: ATM Signaling-Dependent Induction of Nonhomologous End Joining (NHEJ) in G1 and Resection-Mediated Inhibition of NHEJ in G2. Mol. Cell. Biol. 29, 5552-5563. doi:10.1128/mcb.00476-09.

Dyer, M. A., Qadeer, Z. A., Valle-Garcia, D., and Bernstein, E. (2017). ATRX and DAXX: Mechanisms and Mutations. Cold Spring Harb. Perspect. Med. 7, a026567. doi:10.1101/cshperspect.a026567.

Flynn, R. L., Chang, S., and Zou, L. (2012). RPA and POT1: friends or foes at telomeres? Cell Cycle 11, 652-7. doi:10.4161/cc.11.4.19061.

Flynn, R. L., Cox, K. E., Jeitany, M., Wakimoto, H., Bryll, A. R., Ganem, N. J., et al. (2015). Alternative lengthening of telomeres renders cancer cells hypersensitive to ATR inhibitors. Science 347, 273-7. doi:10.1126/science.1257216.

Frohnert, C., Hutten, S., Wälde, S., Nath, A., and Kehlenbach, R. H. (2014). Importin 7 and Nup358 promote nuclear import of the protein component of human telomerase. PLoS One 9. doi:10.1371/journal.pone.0088887.

Jeong, S. A., Kim, K., Lee, J. H., Cha, J. S., Khadka, P., Cho, H. S., et al. (2015). Akt-mediated phosphorylation increases the binding affinity of hTERT for importin $\alpha$ to promote nuclear translocation. J. Cell Sci. doi:10.1242/jcs.166132.

Jia-Min Zhang, A., Yadav, T., Ouyang, J., Lan, L., and Zou Correspondence, L. (2019). Alternative Lengthening of Telomeres through Two Distinct Break-Induced Replication Pathways. CellReports 26, 955-968.e3. doi:10.1016/j.celrep.2018.12.102.

Jiang, W.-Q., Zhong, Z.-H., Henson, J. D., Neumann, A. A., Chang, A. C.-M., and Reddel, R. R. (2005). Suppression of Alternative Lengthening of Telomeres by Sp100-Mediated Sequestration of the MRE11/RAD50/NBS1 Complex. Mol. Cell. Biol. 25, 27082721. doi:10.1128/MCB.25.7.2708-2721.2005.

Lafrance-Vanasse, J., Williams, G. J., and Tainer, J. A. (2015). Envisioning the dynamics and flexibility of Mre11-Rad50-Nbs1 complex to decipher its roles in DNA replication and repair. Prog. Biophys. Mol. Biol. 117, 182-193. doi:10.1016/j.pbiomolbio.2014.12.004.

Lee, J. H., Khadka, P., Baek, S. H., and Chung, I. K. (2010). CHIP promotes hTERT degradation and negatively regulates telomerase activity. J. Biol. Chem. 285, 42033-42045. doi:10.1074/jbc.M110.149831.

Lovejoy, C. A., Li, W., Reisenweber, S., Thongthip, S., Bruno, J., de Lange, T., et al. (2012). Loss of ATRX, genome instability, and an altered DNA damage response are hallmarks of the alternative lengthening of telomeres pathway. PLoS Genet. 8, e1002772. doi:10.1371/journal.pgen.1002772.

Min, J., Wright, W. E., and Shay, J. W. (2019). Clustered telomeres in phase-separated nuclear condensates engage mitotic DNA synthesis through BLM and RAD52. Genes Dev. 33, 814-827. doi:10.1101/gad.324905.119.

Moon, D. H., Segal, M., Boyraz, B., Guinan, E., Hofmann, I., Cahan, P., et al. (2015). Poly(A)-specific ribonuclease (PARN) mediates 3'-end maturation of the telomerase RNA component. Nat. Genet. 47, 1482-1488. doi:10.1038/ng.3423.

Potts, P. R., and Yu, H. (2007). The SMC5/6 complex maintains telomere length in ALT cancer cells through SUMOylation of telomere-binding proteins. Nat. Struct. Mol. Biol. 14, 581-90. doi:10.1038/nsmb1259.

Schmidt, J. C., and Cech, T. R. (2015). Human telomerase: Biogenesis, trafficking, recruitment, and activation. Genes Dev. 29, 1095- 
1105. doi:10.1101/gad.263863.115.

Sobinoff, A. P., Allen, J. A., Neumann, A. A., Yang, S. F., Walsh, M. E., Henson, J. D., et al. (2017). BLM and SLX4 play opposing roles in recombination-dependent replication at human telomeres. EMBO J. 36, 2907-2919. doi:10.15252/embj.201796889.

Tseng, C.-K., Wang, H.-F., Burns, A. M., Schroeder, M. R., Gaspari, M., and Baumann, P. (2015). Human Telomerase RNA Processing and Quality Control. Cell Rep. 13, 2232-2243. doi:10.1016/j.celrep.2015.10.075.

Venteicher, A. S., Meng, Z., Mason, P. J., Veenstra, T. D., and Artandi, S. E. (2008). Identification of ATPases Pontin and Reptin as Telomerase Components Essential for Holoenzyme Assembly. Cell 132, 945-957. doi:10.1016/j.cell.2008.01.019.

Zhu, X. D., Niedernhofer, L., Kuster, B., Mann, M., Hoeijmakers, J. H. J., and De Lange, T. (2003). ERCC1/XPF Removes the 3' Overhang from Uncapped Telomeres and Represses Formation of Telomeric DNA-Containing Double Minute Chromosomes. Mol. Cell. doi:10.1016/S1097-2765(03)00478-7.

This is a provisional file, not the final typeset article 